\title{
Adsorption of Fluorinated Methane Derivatives at the Surface of Ice under Tropospheric Conditions, As Seen from Grand Canonical Monte Carlo Simulations
}

\author{
Ildikó Sumi ${ }^{\mathrm{a}}$, Balázs Fábián, ${ }^{\mathrm{b}, \mathrm{c}}$ Sylvain Picaud ${ }^{\mathrm{b}}$, Pál Jedlovszky ${ }^{\mathrm{a}, \mathrm{d}, *}$
}

${ }^{a}$ EKF Department of Chemistry, Leányka u. 6, H-3300 Eger, Hungary

${ }^{\mathrm{b}}$ Institut UTINAM (CNRS UMR 6213), Université de Franche-Comté, 16 route de Gray, F-25030 Besançon, France

${ }^{\mathrm{c}}$ Department of Inorganic and Analytical Chemistry, Budapest University of Technology and Economics, Szt. Gellért tér 4, H-1111 Budapest, Hungary

${ }^{\mathrm{d}}$ MTA-BME Research Group of Technical Analytical Chemistry, Szt. Gellért tér 4, H-1111 Budapest, Hungary

Running title: Adsorption of fluorinated methane derivatives on ice

*E-mail: pali@chem.elte.hu, phone: +36-1-3722500 


\section{Abstract:}

The adsorption of the fluorinated methane derivatives, $\mathrm{CH}_{\mathrm{n}} \mathrm{F}_{4-\mathrm{n}}$, at the (0001) surface of $\mathrm{I}_{\mathrm{h}}$ ice is studied by grand canonical Monte Carlo computer simulation at the tropospheric temperature of $200 \mathrm{~K}$. It is found that $\mathrm{CH}_{4}$ and $\mathrm{CF}_{4}$ adsorbs rather weakly, while $\mathrm{CH}_{3} \mathrm{~F}, \mathrm{CH}_{2} \mathrm{~F}_{2}$ and $\mathrm{CHF}_{3}$ exhibit multilayer adsorption. The vapor phase of $\mathrm{CH}_{4}$ and $\mathrm{CF}_{4}$ turns out to be rather dense, in accordance with the fact that $\mathrm{CF}_{4}$ is already rather close to, while $\mathrm{CH}_{4}$ is already above its critical point. Adsorbed $\mathrm{CH}_{3} \mathrm{~F}$ molecules, being in contact with the ice phase, turn with their $\mathrm{H}$ atoms towards the ice surface, forming several weak, $\mathrm{C}-\mathrm{H}$ donated hydrogen bonds with the surface water molecules. By contrast, $\mathrm{CH}_{2} \mathrm{~F}_{2}$ and $\mathrm{CHF}_{3}$ molecules are found to turn at least one of their $\mathrm{F}$ atoms towards the ice phase, forming strong, $\mathrm{O}-\mathrm{H}$ donated hydrogen bonds with surface waters, in accordance with former infrared (IR) spectroscopy data. Once all hydrogen bonding positions are occupied, the first molecular layer of these molecules is not yet saturated. Thus, further molecules can be adsorbed in contact with the ice phase, but without forming hydrogen bonds with it. 


\section{Introduction}

Solid water surfaces in ice clouds and snowflakes are now recognized to play important roles in a variety of atmospheric phenomena ranging from catalytic ozone destruction due to halogen activation in the polar stratosphere [!1] to organic compound scavenging by falling snow.[!2] Indeed, the impact of ice-halogen chemistry on the formation of the Antarctic ozone hole was definitely quantified at the end of the last century, and was related to halogen released from ice particles that are interacting with long-lived anthropogenic substances, such as chlorofluorocarbons (CFCs) in Polar Stratospheric Clouds.[!3] This led to the signing of the Montreal Protocol in 1987, which resulted in a significant decrease of the global production and use of CFCs, these chemical substances being progressively replaced first by hydrochlorofluorocarbons (HCFCs) and, in a second step, by hydrofluorocarbons (HFCs).[!4] Indeed, like CFCs, the entirely synthetic HFC compounds can be used not only in refrigeration and air conditioning, but also as foam agents, medical aerosols, fire retardants, and solvents.[!5,6]

Unfortunately, HFCs are greenhouse gases and, because their atmospheric concentrations are rapidly increasing, their contribution to anthropogenic greenhouse gas emissions is causing international concern about their influence on climate, which is now estimated to reach up to $19 \%$ of the projected $\mathrm{CO}_{2}$ radiative forcing in 2050.[!7,8] Moreover, it has been recently inferred that, by increasing tropospheric and stratospheric temperatures, these strong radiative forcers might indirectly enhance ozone-destroying catalytic cycles.[!6]

HFCs are long-lived chemicals with slow gas phase reactions, therefore they may remain in the atmosphere for many years unless scavenged from the gas phase, for instance, by dissolution into water droplets or trapping at the surface of ice particles.[!9] The characterization of their interaction with water and/or ice surfaces is thus of fundamental importance to better estimate their atmospheric fate. However, and surprisingly, the interaction of HFCs with ice surfaces has scarcely been studied in the literature, and we are aware of only a handful of (rather old) related experimental papers. For instance, Buch et al. used infrared (IR) spectroscopy measurements to characterize the surface of ice nanocrystals through the analysis of the asymmetric $\mathrm{C}-\mathrm{F}$ stretch of adsorbed $\mathrm{CF}_{4}$ molecules, used as surface probes, at 83 K.[!10] More related to our purpose, Holmes and Sodeau studied the interaction between 
amorphous ice and a series of twenty-three halogenocarbon compounds, including compounds corresponding to the general formula $\mathrm{CH}_{\mathrm{n}} \mathrm{F}_{4-\mathrm{n}}$, by means of IR spectroscopy measurements at $12 \mathrm{~K} .[! 11]$ They found that all these molecules interact through lone pair donation from a halogen atom to a dangling hydrogen atom of the water molecules at the surface of ice, and that the IR shift of the corresponding dangling $\mathrm{O}-\mathrm{H}$ bond strongly depends on the nature of the halogenocarbon molecule. At the same time, Graham et al., used helium atom scattering to characterize, under ultrahigh vacuum conditions, the adsorption of $\mathrm{CHF}_{3}$ at the (0001) surface of $\mathrm{I}_{\mathrm{h}}$ ice, and showed that these molecules can form an ordered overlayer at temperatures below $75 \mathrm{~K}$, in which the $\mathrm{CHF}_{3}$ molecules are aligned most probably with their $\mathrm{H}$-atoms pointing downwards.[!12] Later, Martin et al. characterized the adsorption of $\mathrm{CF}_{4}$ on amorphous ice by volumetric and Fourier transform IR co-measurements at $95 \mathrm{~K}$, showing that $\mathrm{CF}_{4}$ does not wet the ice surface and that the layer growth is probably achieved by three-dimensional clustering on the amorphous ice surface.[!13] It should be noted that, not only scarce, these experiments have been conducted in conditions far from those encountered in the upper troposphere/lower stratosphere and, as a consequence, their conclusions are of little interest for atmospheric sciences. In contrast, a more recent work by Moreno et al. provided uptake results of trifluoroethanol $\left(\mathrm{CF}_{3} \mathrm{CH}_{2} \mathrm{OH}\right)$ on ice over the temperature range of $203-223 \mathrm{~K}$ using a coated wall flow tube coupled to mass spectrometric detection.[19] The results showed that over pure ice the adsorption of this molecule is fully reversible and can be described in terms of the Langmuir isotherm for the range of concentrations and temperatures investigated, with an adsorption enthalpy value of $-46 \pm 16 \mathrm{~kJ} / \mathrm{mol}$. Moreover, from these results it was inferred that while ice surfaces in cirrus clouds may retain only $1.5 \%$ of $\mathrm{CF}_{3} \mathrm{CH}_{2} \mathrm{OH}$, snow can behave as an efficient reservoir for this molecule because of the large density areas of snowpack in the Arctic boundary layer that may enhance the gas/ice partitioning up to $41 \%$ at 223 K.[!9]

Experimental investigations can, in principle, be well complemented by computer simulation studies, as in computer simulations a more detailed insight at the molecular level can be obtained into a suitably chosen model of the system of interest than what can be provided by any experiment. In spite of this, computer simulation studies of the adsorption of halomethanes at atmospheric surfaces are also scarce. To quantify the thermodynamic driving force of this adsorption at infinitely low surface density, we calculated the solvation free energy profile of several fluorinated (i.e., $\left.\mathrm{CH}_{2} \mathrm{~F}_{2}\right)$ and chlorinated $\left(\mathrm{CH}_{2} \mathrm{Cl}_{2}, \mathrm{CHCl}_{3}\right)$ methane 
derivatives across the ice/air and water/air interfaces. [!14] Similar study was later performed by Habartová et al. concerning the free energy profile of all the partially chlorinated and brominated methane derivatives at the water/air interface. [!15] Later they also studied the adsorption of these molecules at the surface of $I_{h}$ ice at infinitely low surface density by molecular dynamics simulations. [!16] Finally, in a recent study, using the grand canonical Monte Carlo (GCMC) simulation method [!17,18] we investigated in detail the adsorption process of $\mathrm{CH}_{2} \mathrm{~F}_{2}$ and $\mathrm{CH}_{2} \mathrm{Cl}_{2}$ at the surface of $\mathrm{I}_{\mathrm{h}}$ ice under tropospheric conditions. [!19] The GCMC method is particularly suitable for studying adsorption, because in this method the chemical potential rather than the number of the adsorbate molecules is fixed in the simulation. As a consequence, by systematically varying the value of this chemical potential in a series of GCMC simulations, and determining the number of the adsorbed molecules per surface unit as a function of it, the adsorption isotherm can be directly calculated, and deeper analyses can always be performed at physically relevant surface coverages. Indeed, the GCMC method has successfully been applied to study the adsorption of small molecules at various solid surfaces, such as ice, [!19-24] metal oxides, [!25-27] kaolinite, [!28,29] zeolites, [!30-35] protein crystals, [!36] covalent organic frameworks, [!37-39] carbonaceous materials, [!40-45] or selfassembled monolayers [!46,47] several times.

Our former results concerning the adsorption of $\mathrm{CH}_{2} \mathrm{~F}_{2}$ and $\mathrm{CH}_{2} \mathrm{Cl}_{2}$ at the surface of ice revealed that the adsorption behavior of these two molecules is markedly different from each other, [!19] thus raising interest for systematic studies on halogenocarbon adsorption on ice. For this reason, we present here a detailed investigation of the adsorption behavior of the $\mathrm{CH}_{n} \mathrm{~F}_{4-\mathrm{n}}$ molecules at the surface of $\mathrm{I}_{\mathrm{h}}$ ice under tropospheric conditions by performing GCMC simulations. One might expect rather different adsorption behavior of these compounds, since several of their physical properties that might be related to the adsorption, such as the dipole moment, melting and boiling point or the critical temperature scatter in a rather broad range of values, as seen from Table 1. Besides the adsorption isotherms, the layering of the adsorbed molecules as well as the orientation and binding energy of the adsorbed molecules that are in direct contact with the ice phase are also analyzed in detail. The paper is organized as follows. In sec. 2 details of the calculations performed are given. The obtained results are presented in sec. 3 , and in sec. 4 the main conclusions of this study are discussed and summarized. 


\section{Computer Simulations}

The adsorption of methane and its four partially or fully fluorinated derivatives, i.e., $\mathrm{CH}_{4}, \mathrm{CH}_{3} \mathrm{~F}, \mathrm{CH}_{2} \mathrm{~F}_{2}, \mathrm{CHF}_{3}$, and $\mathrm{CF}_{4}$ at the (0001) surface of $\mathrm{I}_{\mathrm{h}}$ ice has been studied by performing a set of Monte Carlo simulations on the grand canonical $(\mu, V, T)$ ensemble at the temperature of $T=200 \mathrm{~K}$. The basic simulation box has consisted of 2880 water molecules, arranged in 18 molecular layers according to the geometry of the $\mathrm{I}_{\mathrm{h}}$ ice crystal. The $L_{\mathrm{X}}, L_{\mathrm{Y}}$, and $L_{\mathrm{Z}}$ edge lengths of the basic simulation box along the $\mathrm{X}, \mathrm{Y}$, and $\mathrm{Z}$ axes of an external Cartesian frame have been set to $100.0,38.891$, and $35.926 \AA$, respectively, $\mathrm{X}$ being the surface normal axis. The values of $L_{Y}$ and $L_{Z}$ have been set according to the periodicity of the ice crystal along the $\mathrm{Y}$ and $\mathrm{Z}$ axes, respectively. In each of the simulations the chemical potential of the adsorbate, $\mu$, has been systematically varied from values corresponding to practically no adsorbate molecules in the basic box to those corresponding to a dense (condensed) phase of the adsorbate. To access the adsorption isotherms, the average number of the adsorbate molecules in the basic box, $\langle N\rangle$, has been recorded as the function of the chemical potential. The $\mu$ values used in the simulations are collected in Tables S1-S5 of Supporting Information.

The methane derivative adsorbate molecules have been described by the force field proposed by Palmer and Anchell for exactly this set of molecules, [!49] whereas water has been modeled by the TIP5P potential, [!50] since this model reproduces the melting point of $I_{h}$ ice rather accurately. [!51,52] According to these potential models, the total potential energy of the system has been calculated as the sum of the contributions of all molecule pairs, and the interaction energy of the $i$ th and $j$ th molecule, $u_{i j}$, has been calculated as the sum of the Lennard-Jones and Coulomb contributions of all pairs of their interaction sites:

$$
u_{i j}=\sum_{\alpha=1}^{N_{i}} \sum_{\beta=1}^{N_{j}} \frac{1}{4 \pi \in_{0}} \frac{q_{\alpha} q_{\beta}}{r_{i \alpha, j \beta}}+4 \varepsilon_{\alpha \beta}\left[\left(\frac{\sigma_{\alpha \beta}}{r_{i \alpha, j \beta}}\right)^{12}-\left(\frac{\sigma_{\alpha \beta}}{r_{i \alpha, j \beta}}\right)^{6}\right]
$$

In this equation, the indices $\alpha$ and $\beta$ run over the $N_{i}$ and $N_{j}$ interaction sites of molecule $i$ and $j$, respectively, $q_{\alpha}$ and $q_{\beta}$ are the fractional charges carried by the respective interaction sites, $\in_{0}$ is the vacuum permittivity, $r_{i \alpha, j \beta}$ is the distance between site $\alpha$ on molecule $i$ from site $\beta$ on 
molecule $j$, while $\varepsilon_{\alpha \beta}$ and $\sigma_{\alpha \beta}$ are the Lennard-Jones energy and distance parameters, respectively, corresponding to the site pair $\alpha$ and $\beta$, derived from the values corresponding to the individual sites through the Lorentz-Berthelot rule, [!18] i.e., $\varepsilon_{\alpha \beta}=\left(\varepsilon_{\alpha} \varepsilon_{\beta}\right)^{1 / 2}$ and $\sigma_{\alpha \beta}=\left(\sigma_{\alpha}+\sigma_{\beta}\right) / 2$. All the molecular models used have been rigid, and all interactions have been truncated to zero beyond the center-center cut-off distance of $12.5 \AA$ A According to the original parameterization of all the potential models used here, [!49,50] no long range correction has been applied for the electrostatic interaction. The interaction and geometry parameters of the molecular models used are collected in Tables 2 and 3, respectively. It should be noted that in our previous work we already studied the adsorption of $\mathrm{CH}_{2} \mathrm{~F}_{2}$ at the surface of ice, [!19] however, by using another model of $\mathrm{CH}_{2} \mathrm{~F}_{2}$, namely the Jedlovszky-Mezei (JM) potential. [!53] This fact will allow us to address also the model dependence of the results. To test the validity of the models used to describe the adsorbate molecules, we have performed molecular dynamics (MD) simulations of the neat bulk fluid phase of these models at $200 \mathrm{~K}$ and 1 bar (using the GROMACS 4.5.5 program package, [!54] performing $20 \mathrm{~ns}$ long equilibration and $10 \mathrm{~ns}$ long production runs). For comparisons, a similar MD simulation has also been performed with the JM model of $\mathrm{CH}_{2} \mathrm{~F}_{2}$. The diffusion coefficient $(D)$, density $(\rho)$ and total potential energy $(U)$ of these systems are collected in Table 4, while their C-C radial distribution functions are shown in Figure S1 of Supporting Information.

The GCMC simulations have been performed using the program MMC. [!55] In a Monte Carlo step either, by 50\% probability, a randomly chosen molecule has been attempted to be randomly translated and rotated around a randomly chosen axis parallel with one of the edges of the basic box, or the number of the adsorbate molecules has been attempted to be changed by inserting or deleting a molecule. In molecule displacement steps the translation and rotation have not exceeded the values of $0.25 \AA$ and $15^{\circ}$, respectively; these steps have been accepted or rejected according to the standard Metropolis criterion. [!18,56] Insertion and deletion attempts, performed with equal probabilities, have been done according to the cavity biased scheme of Mezei. [!57,58] Thus, molecules have only been tried to be inserted into empty cavities the radius of which has been at least $2.5 \AA$. Cavities have been searched for along a $100 \times 100 \times 100$ grid, which has been regenerated after every $10^{6}$ Monte Carlo steps. Insertion/deletion attempts have been accepted or rejected according to the acceptance rule of the cavity biased method. [!57,58] The probability of finding a suitable cavity, $P_{\text {cav }}$, used in this 
acceptance criterion has simply been obtained as the ratio of cavities found and grid points tested. At least $0.1 \%$ of the insertion/deletion and $10 \%$ of the particle displacement attempts have turned out to be successful in every case.

The simulations have started from a perfect $I_{h}$ ice crystal, with two adsorbate molecules placed randomly in the vapor phase. The ice phase has been placed in the middle of the basic box along its $\mathrm{X}$ axis. Standard periodic boundary conditions have been applied in all three directions. Due to this periodicity, the basic box has contained two ice surfaces. All results have been obtained by averaging over these two surfaces. The systems have been equilibrated by performing $3 \times 10^{8}$ Monte Carlo steps. Then, the average number of the adsorbate molecules in the basic box, $\langle N\rangle$, has been calculated in a trajectory generated by performing another $10^{8}$ Monte Carlo steps. In the case of systems containing $\mathrm{CH}_{4}$ or $\mathrm{CF}_{4}, 500$ sample configurations, separated by $2 \times 10^{5}$ Monte Carlo steps each, have been saved from this trajectory to calculate the adsorbate density profiles, and the value of their surface excess. For the other three systems, 2500 independent sample configurations, separated by $2 \times 10^{5}$ Monte Carlo steps long trajectories each, have been dumped from a subsequent $5 \times 10^{8}$ Monte Carlo steps long trajectory for detailed analyses at five selected chemical potential values (see Tables S2-S4 of Supporting Information).

\section{Results}

3.1. Adsorption Isotherms. The average number of the $\mathrm{CH}_{\mathrm{n}} \mathrm{F}_{4-\mathrm{n}}$ adsorbate molecules present in the basic box, $\langle N\rangle$, is shown as a function of the adsorbate chemical potential, $\mu$, in Figure 1, whereas the corresponding data are collected in Tables S1-S5 of Supporting Information. For systems in which practically all adsorbate molecules belong to the adsorption layer, this $\langle N\rangle(\mu)$ curve agrees with the adsorption isotherm, the chemical potential being its independent variable. In the present study, the systems containing $\mathrm{CH}_{3} \mathrm{~F}, \mathrm{CH}_{2} \mathrm{~F}_{2}$, and $\mathrm{CHF}_{3}$ have turned out to be such systems. On the other hand, when the adsorbate molecule has been $\mathrm{CH}_{4}$ or $\mathrm{CF}_{4}$, the vapor phase of the system contained also non-adsorbed molecules in a quantity that is comparable with that of the adsorbed ones. The reason for this behavior is that the

simulation temperature of $200 \mathrm{~K}$ is rather close to the critical point of these molecules (the experimental critical temperature of $\mathrm{CH}_{4}$ and $\mathrm{CF}_{4}$ being $190.6 \mathrm{~K}$ and $227.7 \mathrm{~K}$, [!48] 
respectively, see Table 1). It should be noted that the experimental critical point of $\mathrm{CH}_{4}$ is even below the simulation temperature by about $10 \mathrm{~K}$, and the behavior of the simulated $\langle N\rangle(\mu)$ data, i.e., its continuous increase in the entire chemical potential range and lack of a sharp, sudden jump suggests that the $\mathrm{CH}_{4}$ model used in the simulations is also supercritical at the simulation temperature. Although the $\mathrm{CF}_{4}$ model used seems to be still below its critical point, it is already rather close to it, and hence the difference between the liquid and vapor phases is rather small: the vapor phase is dense and the liquid phase is of low density. Our conclusion that the used model of $\mathrm{CH}_{4}$ is already above its critical point is also supported by the diffusion coefficient, density and internal energy values (see Table 4) and carbon-carbon radial distribution function (see Fig. S1 of Supporting Information), obtained from bulk MD simulation at $200 \mathrm{~K}$.

The $\langle N\rangle(\mu)$ data obtained for the four fluorine-containing adsorbates, in contrast with that of $\mathrm{CH}_{4}$, exhibit a very sharp jump at well defined chemical potential values, indicating condensation of the adsorbate at this $\mu$ value, and the presence of a liquid rather than vapor phase above it. The chemical potential value corresponding to the condensation of $\mathrm{CH}_{3} \mathrm{~F}$, $\mathrm{CH}_{2} \mathrm{~F}_{2}, \mathrm{CHF}_{3}$, and $\mathrm{CF}_{4}$ turned out to be $-25.09,-45.56,-30.48$, and $-24.55 \mathrm{~kJ} / \mathrm{mol}$, respectively. The vicinity of the critical point of $\mathrm{CF}_{4}$ is also reflected in the high compressibility of the liquid phase, seen from the large slope of the liquid branch of the $\langle N\rangle(\mu)$ data. Since $\mathrm{CH}_{4}$ is already above its critical point at the temperature of the simulations, the number of $\mathrm{CH}_{4}$ molecules changes continuously with the chemical potential value. Nevertheless, by calculating the derivative of the $\langle N\rangle(\mu)$ data numerically, one can determine the chemical potential value at which the $\langle N\rangle(\mu)$ data is of maximum slope, i.e., the compressibility of $\mathrm{CH}_{4}$ is the largest. This $\mu$ value, turned out to be $-16.75 \mathrm{~kJ} / \mathrm{mol}$, lays along the so-called Widom line, i.e., the supercritical extension of the vapor-liquid coexistence curve, where the thermodynamic response functions (e.g., the compressibility) of the supercritical system go through a finite maximum. When comparing the five $\langle N\rangle(\mu)$ data sets it is seen that the adsorption of $\mathrm{CH}_{2} \mathrm{~F}_{2}$ starts at considerably smaller, and that of $\mathrm{CF}_{4}$ and $\mathrm{CH}_{4}$ at considerably larger chemical potential values than that of the other molecules, and also that $\mathrm{CH}_{2} \mathrm{~F}_{2}$ condenses much earlier than the other four molecules considered. The first finding indicates a much higher affinity of $\mathrm{CH}_{2} \mathrm{~F}_{2}$ (and much smaller affinity of $\mathrm{CH}_{4}$ and $\mathrm{CF}_{4}$ ) to ice, while the second one reflects the significantly larger cohesion of $\mathrm{CH}_{2} \mathrm{~F}_{2}$ than that of the other molecules. 
To further analyze the obtained adsorption isotherms, we have converted the $\langle N\rangle(\mu)$ data sets to the more conventional $\Gamma\left(p_{\text {rel }}\right)$ form, where $\Gamma$ is the surface excess, and $p_{\text {rel }}=p / p_{0}$ is the relative pressure, i.e., the pressure, $p$, normalized by that of the saturated vapor, $p_{0}$. Having the chemical potential value corresponding to the point of condensation, $\mu_{0}$, detected, $p_{\text {rel }}$ can simply be calculated as [!26]

$$
p_{\text {rel }}=\frac{p}{p_{0}}=\frac{\exp (\beta \mu)}{\exp \left(\beta \mu_{0}\right)}
$$

where $\beta=1 / k_{\mathrm{B}} T$, and $k_{\mathrm{B}}$ is the Boltzmann constant. In the case of $\mathrm{CH}_{4}$, when no condensation occurs, we used the $\mu$ value corresponding to the Widom line (i.e., to the maximum steepness of the $\langle N\rangle(\mu)$ data) as $\mu_{0}$. For $\mathrm{CH}_{3} \mathrm{~F}, \mathrm{CH}_{2} \mathrm{~F}_{2}$ and $\mathrm{CHF}_{3}$, i.e., when the bulk vapor phase density turned out to be practically zero at every chemical potential value up to the point of condensation, $\Gamma$ has simply been calculated as

$$
\Gamma=\frac{<N>}{2 L_{Y} L_{Z}},
$$

where the factor of 2 in the denominator accounts for the two ice surfaces present in the basic simulation box. For $\mathrm{CH}_{4}$ and $\mathrm{CF}_{4}$, on the other hand, $\Gamma$ has been calculated as the surface excess with respect to an idealized situation, in which the density is constant at the vapor side of the Gibbs dividing surface and zero at its ice side: $[! 59,60]$

$$
\Gamma=\int_{0}^{X_{\mathrm{G}}} \rho(X) \mathrm{d} X+\int_{X_{\mathrm{G}}}^{L_{\mathrm{X}}}\left(\rho(X)-\rho_{\mathrm{vap}}\right) \mathrm{d} X .
$$

Here $X_{\mathrm{G}}$ is the position of the Gibbs dividing surface along the surface normal axis, $\mathrm{X}, \rho(X)$ is the number density profile of the adsorbate along the $\mathrm{X}$ axis, and $\rho_{\text {vap }}$ is the bulk vapor phase density, calculated here as the mean value of $\rho(X)$ in the $X$ range between 45 and $50 \AA$. The $\rho(X)$ molecular number density profiles of $\mathrm{CH}_{4}$ and $\mathrm{CF}_{4}$ are shown in Figure 2 as obtained at selected chemical potential values. The inset of the figure shows the bulk vapor/gas part of these profiles, demonstrating that the bulk phase density of these systems is indeed different from zero. The value of $X_{\mathrm{G}}$ in eq. 4 has been determined from the condition that no adsorption 
is possible from the liquid phase, i.e., $\Gamma=0$ above the point of condensation. This way, in contrast with the raw $\langle N\rangle(\mu)$ data, the $\Gamma\left(p_{\text {rel }}\right)$ isotherms indeed account only for the amount of the adsorbed molecules in the system. It should also be noted that in the case of adsorbates being below their critical point $p_{\text {rel }}$ cannot exceed unity, as $p_{\text {rel }}=1$ marks the point of condensation, but for $\mathrm{CH}_{4}$, being already above its critical point, $p_{\text {rel }}$ values above 1 are also physically meaningful, as they simply correspond to the state of a dense gas. However, in this case, the value of $\Gamma$ increases up to about $p_{\text {rel }}=1$, i.e., when the bulk gas phase is of low density (as adsorption is defined as an excess with respect to the bulk gas phase density, which is small here), and rapidly decreases above $p_{\text {rel }}=1$, when the bulk gas phase density is rather high.

The $\Gamma\left(p_{\text {rel }}\right)$ adsorption isotherms obtained from our simulations are presented in Figure 3, and the corresponding data are also included in Tables S1-S5 of Supporting Information. As is seen, the isotherms corresponding to $\mathrm{CH}_{3} \mathrm{~F}, \mathrm{CH}_{2} \mathrm{~F}_{2}$ and $\mathrm{CHF}_{3}$ exhibit a linear increase at low $p_{\text {rel }}$ values, then the slope of the curve decreases, but before reaching a plateau it rises sharply again at high $p_{\text {rel }}$ values. This behavior is characteristic to class II isotherms according to the IUPAC convention, and indicates multilayer adsorption. This multilayer adsorption is clearly the strongest for $\mathrm{CH}_{3} \mathrm{~F}$, and weakest for $\mathrm{CH}_{2} \mathrm{~F}_{2}$, for which the isotherm goes only slightly above the monolayer saturation value at $p_{\text {rel }}$ values above 0.8 . This behavior is somewhat different from what was previously observed for $\mathrm{CH}_{2} \mathrm{~F}_{2}$ with the JM potential model, when the multilayer adsorption turned out to be much more pronounced than here. [!19] Nevertheless, the qualitative behavior of the two models of $\mathrm{CH}_{2} \mathrm{~F}_{2}$ are similar to each other.

Class II isotherms describe that type of multilayer adsorption when the first layer gets more or less saturated before the outer layers start building up. This allows us to fit the Langmuir isotherm, [!61,62] i.e.,

$$
\Gamma=\Gamma_{\max } \frac{p_{\text {rel }} K}{1+p_{\text {rel }} K}
$$

to the $\Gamma\left(p_{\text {rel }}\right)$ data up to a certain $p_{\text {rel }}$ value, being below the pressure at which the building up of the outer layers begins. In the above equation $\Gamma_{\max }$ is the surface density (surface excess) of the saturated monolayer, and $K$ is the Langmuir partition coefficient. In the present case, the $\Gamma\left(p_{\text {rel }}\right)$ data have turned out to follow the Langmuir isotherm up to the $p_{\text {rel }}$ values of about $0.15,0.2$, 
and 0.65 for $\mathrm{CH}_{3} \mathrm{~F}, \mathrm{CHF}_{3}$, and $\mathrm{CH}_{2} \mathrm{~F}_{2}$, respectively. The Langmuir isotherms fitted to the simulation data up to these relative pressures are also included in Fig. 3 (dashed lines). The $\Gamma_{\max }$ and $K$ values obtained for $\mathrm{CH}_{3} \mathrm{~F}, \mathrm{CH}_{2} \mathrm{~F}_{2}$, and $\mathrm{CHF}_{3}$ are $7.46 \mu \mathrm{mol} / \mathrm{m}^{2}$ and 23.0, $6.74 \mu \mathrm{mol} / \mathrm{m}^{2}$ and 3.78 , and $7.04 \mu \mathrm{mol} / \mathrm{m}^{2}$ and 12.5 , respectively. It should be noted that multilayer adsorption can often be well described by the Brunauer-Emmett-Teller (BET) isotherm, [!62] however, in our case neither of the three $\Gamma\left(p_{\text {rel }}\right)$ data sets have turned out to be consistent with this description, as the BET fit of all of them are rather poor.

For a further, detailed analysis we have only considered the systems containing $\mathrm{CH}_{3} \mathrm{~F}$, $\mathrm{CH}_{2} \mathrm{~F}_{2}$, and $\mathrm{CHF}_{3}$. For this purpose, we have collected 2500 independent sample configurations at five different chemical potential values for all these three adsorbates, in such a way that they include systems characterized by an unsaturated monolayer, a more or less saturated monolayer, multilayer adsorption, as well as condensed phase of the adsorbate in every case. The five selected state points are marked as MF1, MF2, MF3, MF4, and MF5 for $\mathrm{CH}_{3} \mathrm{~F}$ (MF standing for methyl fluoride) in such a way that MF1 corresponds to the system of the lowest, and MF5 to that of the highest chemical potential value. Similarly, for $\mathrm{CH}_{2} \mathrm{~F}_{2}$ the five selected systems ate denoted by MeF1, MeF2, MeF3, MeF4, and MeF5 (MeF standing for methylene fluoride), and for $\mathrm{CHF}_{3}$ by FF1, FF2, FF3, FF4, and FF5 (FF standing for fluoroform). These state points are marked in Figures 1 and 3, and the corresponding chemical potential values are indicated in Tables S2-S4 of Supporting Information. An equilibrium snapshot of systems MF2, MF4 and MF5, those of MeF2, MeF4 and MeF5, and those of FF2, FF4, and FF5 are shown in panels a, b, and c of Figure 4, respectively, for illustration.

3.2. Density Profiles. The molecular number density profiles of $\mathrm{CH}_{3} \mathrm{~F}, \mathrm{CH}_{2} \mathrm{~F}_{2}$, and $\mathrm{CHF}_{3}$ in states MF1-MF5, MeF1-MeF5, and FF1-FF5, respectively, are shown in Figure 5 (the position of the molecules being estimated by that of their $\mathrm{C}$ atom). For reference, the water number density profile in system MF1 is shown in the inset of this figure; this profile has turned out to be very similar in every system considered. As is seen, systems MF2 and FF3 are characterized by a more or less saturated monolayer, in systems MF3 and FF4 two, whereas in MF4 three layers of adsorbed molecules can be clearly distinguished. In the case of $\mathrm{CH}_{2} \mathrm{~F}_{2}$, on the other hand, the first molecular layer is not yet saturated even in system MeF4, and even traces of the second molecular layer can hardly be seen from the profile. This finding seems to 
contradict our conclusions, drawn from the shape of the adsorption isotherm, concerning multilayer adsorption of $\mathrm{CH}_{2} \mathrm{~F}_{2}$, even if a few $\mathrm{CH}_{2} \mathrm{~F}_{2}$ molecules are indeed located in the $X$ range of the second molecular layer in system MeF4. This point is further discussed in a following subsection. Further, in a clear contrast with the density profiles of $\mathrm{CH}_{4}$ and $\mathrm{CF}_{4}$ (Fig. 2), the density profiles of $\mathrm{CH}_{3} \mathrm{~F}, \mathrm{CH}_{2} \mathrm{~F}_{2}$ and $\mathrm{CHF}_{3}$ indeed drop to zero in the middle of the adsorbate phase in every state point below the point of condensation. It is also seen that systems MF5, MeF5 and FF5 are characterized by the liquid phase of the adsorbate. In the liquid phase of $\mathrm{CH}_{3} \mathrm{~F}$ and $\mathrm{CHF}_{3}$ five subsequent molecular layers can be clearly distinguished next to the ice surface, whereas in the case of $\mathrm{CH}_{2} \mathrm{~F}_{2}$ the density profile flattens already beyond the second molecular layer. This feature indicates that $\mathrm{CH}_{2} \mathrm{~F}_{2}$ is considerably farther from its melting point at the simulation temperature than $\mathrm{CH}_{3} \mathrm{~F}$ and $\mathrm{CHF}_{3}$ (as it is also the case for $\mathrm{CF}_{4}$ and $\mathrm{CH}_{4}$, for which only 3-4 molecular layers next to the ice surface can be clearly distinguished in the liquid/dense gas state, see Fig. 2). However, unlike that of $\mathrm{CH}_{4}$ and $\mathrm{CF}_{4}$, the experimental melting point of $\mathrm{CH}_{2} \mathrm{~F}_{2}$ is not farther from the simulation temperature of $200 \mathrm{~K}$ than that of $\mathrm{CH}_{3} \mathrm{~F}$ and $\mathrm{CHF}_{3}$ (see Table 1), suggesting that the potential model of $\mathrm{CH}_{2} \mathrm{~F}_{2}$ used here probably seriously underestimates the melting point.

In the following analyses, we only consider the adsorbed molecules that belong to the first molecular layer at the ice surface. The boundary of this layer can be conveniently defined as the position of the first minimum of the adsorbate density profile in the liquid phase (see the dashed vertical lines in Fig. 5). This way, we have regarded $\mathrm{CH}_{3} \mathrm{~F}, \mathrm{CH}_{2} \mathrm{~F}_{2}$, and $\mathrm{CHF}_{3}$ molecules as belonging to the first molecular layer at the ice surface if their position along the surface normal axis, $X$, have not exceeded $35.8,35.4$, and $36.0 \AA$, respectively.

3.3. Orientation of the Adsorbed Molecules. In order to get more insight into the adsorption process, we have analyzed the orientational statistics of the adsorbed $\mathrm{CH}_{3} \mathrm{~F}, \mathrm{CH}_{2} \mathrm{~F}_{2}$ and $\mathrm{CHF}_{3}$ molecules in the first molecular layer. In describing the orientational statistics of (non-linear) rigid bodies, the bivariate joint distribution of two independent orientational variables has to be calculated. [!63,64] As it was shown previously, the angular polar coordinates, $\vartheta$ and $\phi$, of the surface normal vector in a local Cartesian frame fixed to the individual molecules represent a sufficient choice of such an independent variable pair ( $\vartheta$ and $\phi$ being the angle between the surface normal vector and $z$ axis of the local frame, and that 
between the projection of the surface normal vector to the $x y$ plane and $x$ axis of the local frame, respectively). It should be noted, however, that to ensure that each point of the bivariate orientational distribution corresponds to the same density of orientations (in other words, uncorrelated orientation of the molecules with the surface result in a uniform distribution), $\cos \vartheta$ and $\phi$ are needed to be used as the orientational variables. [!63,64]

Here we define this local Cartesian frame for the different molecules in the following way. For the $\mathrm{CX}_{3} \mathrm{Y}$ molecules, corresponding to the $\mathrm{C}_{3 \mathrm{v}}$ symmetry group, axis $z$ points along the Y-C bond (i.e., F-C bond for $\mathrm{CH}_{3} \mathrm{~F}$, and $\mathrm{H}-\mathrm{C}$ bond for $\mathrm{CHF}_{3}$ ) from the $\mathrm{F} / \mathrm{H}$ towards the $\mathrm{C}$ atom, and one of the three $\mathrm{X}$ atoms (i.e., $\mathrm{H}$ for $\mathrm{CH}_{3} \mathrm{~F}$, and $\mathrm{F}$ for $\mathrm{CHF}_{3}$ ) lays in the $x z$ plane. Due to the symmetry of these molecules, this frame can always be chosen in such a way that the polar angle $\phi$ does not exceed $60^{\circ}$. In the case of $\mathrm{CH}_{2} \mathrm{~F}_{2}$, axis $z$ is the main symmetry axis of the molecule, oriented in such a way that the $z$ coordinates of the $\mathrm{H}$ atoms are negative, while those of the $\mathrm{F}$ atoms are positive, and the $\mathrm{H}$ atoms lay in the $x z$, while the $\mathrm{F}$ atoms in the $y z$ plane of this frame. Due to the symmetry of these molecules, this frame can always be chosen in such a way that the polar angle $\phi$ does not exceed $90^{\circ}$. In every case, the surface normal vector, $\underline{X}$, is oriented in such a way that it points away from the ice phase. The definition of these local Cartesian frames and polar angles $\vartheta$ and $\phi$ for $\mathrm{CH}_{3} \mathrm{~F}, \mathrm{CH}_{2} \mathrm{~F}_{2}$, and $\mathrm{CHF}_{3}$, together with the $P(\cos \vartheta, \phi)$ orientational maps obtained in states MF1-MF5, MeF1-MeF5, and FF1-FF5, respectively, are shown in panels a, b, and c, respectively, of Figure 6.

As is seen from Fig.6.a, the $\mathrm{CH}_{3} \mathrm{~F}$ molecules clearly prefer the orientation characterized by $\cos \vartheta=-1$, in which the C-F bond points straight away from, and the three C-H bonds point flatly towards the ice phase, in every state. In this orientation, marked here as $\mathrm{I}_{\mathrm{MF}}$, the $\mathrm{H}$ atoms of the $\mathrm{CH}_{3} \mathrm{~F}$ molecule can participate in weak, $\mathrm{C}-\mathrm{H}^{\cdots \cdots} \mathrm{O}$ type hydrogen bonds with the surface water molecules aligned in two of their four preferred orientations. [!20] These possible weak, $\mathrm{C}-\mathrm{H}^{\cdots \cdot} \mathrm{O}$ type hydrogen bonding patterns between an adsorbed $\mathrm{CH}_{3} \mathrm{~F}$ and a surface water molecule is illustrated also in Fig. 6.a.

The adsorbed $\mathrm{CH}_{2} \mathrm{~F}_{2}$ molecules have two preferred orientations. In the first one, characterized by $\cos \vartheta \approx-0.3$ and a $\phi$ value close to $90^{\circ}$, one of the C-F bonds of the molecule points straight to the ice phase, while in the other one, corresponding to $\cos \vartheta=-1$ and $\phi=0^{\circ}$, the main symmetry axis of the molecule stays perpendicular to the ice surface, the two F atom pointing towards, while the two $\mathrm{H}$ atoms away from the ice phase. These orientations are 
denoted here as $\mathrm{I}_{\mathrm{MeF}}$ and $\mathrm{II}_{\mathrm{MeF}}$, respectively. Among the two preferred orientations, clearly $\mathrm{II}_{\mathrm{MeF}}$ is found to be the dominant one here, and the preference for alignment $\mathrm{I}_{\mathrm{MeF}}$ even vanishes as the first molecular layer gets more saturated. The $\mathrm{CH}_{2} \mathrm{~F}_{2}$ molecule can participate in strong, $\mathrm{O}-\mathrm{H}^{\cdots \cdots} \mathrm{F}$ type hydrogen bonds with surface water molecules oriented in one of their preferred alignments [!20] both in orientation $\mathrm{I}_{\mathrm{MeF}}$ and $\mathrm{II}_{\mathrm{MeF}}$, as illustrated in Fig. 6.b. This finding is also in a clear accordance with former IR spectroscopy results of Holmes and Sodeau. [!11] In alignment $\mathrm{I}_{\mathrm{MeF}}$ a $\mathrm{CH}_{2} \mathrm{~F}_{2}$ molecule can participate in up to three, while in alignment $\mathrm{II}_{\mathrm{MeF}}$ up to two such hydrogen bonds (i.e., with all the three lone pairs of the downward oriented $\mathrm{F}$ atom in the first, and with both $\mathrm{F}$ atoms in the second case).

In the case of $\mathrm{CHF}_{3}$, the molecules prefer all alignments corresponding to $\cos \vartheta \approx-0.2$, however, as the first molecular layer gets saturated, the two extreme alignments according to the polar angle $\phi$, i.e., the ones corresponding to $\phi=0^{\circ}$ and $\phi=60^{\circ}$ become clearly more preferred than those of intermediate $\phi$ values. In both of these two orientations, marked here as $\mathrm{I}_{\mathrm{FF}}$ and $\mathrm{II}_{\mathrm{FF}}$, respectively, the $\mathrm{C}-\mathrm{H}$ bond points flatly away from the ice surface, declining from it by only about $10^{\circ}$. In alignments $\mathrm{I}_{\mathrm{FF}}$ and $\mathrm{II}_{\mathrm{FF}}$ one of the three $\mathrm{F}$ atoms points as straight away from the ice phase, and as straight towards the ice phase, respectively, as possible. However, since the orientational preference of the $\mathrm{CHF}_{3}$ molecule is very weakly determined in terms of the polar angle $\phi$, all intermediate orientations between $\mathrm{I}_{\mathrm{FF}}$ and $\mathrm{II}_{\mathrm{FF}}$, corresponding to various rotations of the molecule around its $\mathrm{C}-\mathrm{H}$ bond, are also of high probability. In a clear agreement with former experimental results, [!11] the $\mathrm{CHF}_{3}$ molecule can form strong, $\mathrm{O}-\mathrm{H}^{\cdots \cdots} \mathrm{F}$ type hydrogen bonds with the surface water molecules, aligned in one of their preferred orientations, [!20] both in alignment $\mathrm{I}_{\mathrm{FF}}$ and $\mathrm{II}_{\mathrm{FF}}$, as illustrated in Fig. 6.c. In orientation $\mathrm{I}_{\mathrm{FF}}$ the $\mathrm{CHF}_{3}$ molecule can form up to two such hydrogen bonds (i.e., one by both of its downwardoriented $\mathrm{F}$ atoms), while in alignment $\mathrm{II}_{\mathrm{FF}}$ even three such hydrogen bonds might be formed (i.e., one along each lone pair of the downward-oriented $\mathrm{F}$ atom).

3.4. Energetic Background of the Adsorption. To get a more comprehensive understanding of the adsorption process investigated, we calculated the distribution of the binding energy, $U_{\mathrm{b}}$, of the adsorbed molecules belonging to the first molecular layer at the ice surface. The binding energy, $U_{\mathrm{b}}$, of an adsorbed molecule is the total interaction energy of it with the rest of the system, in other words, this is the energy required to bring the given 
molecule at infinite distance from the system. Besides that of the total binding energy, $U_{\mathrm{b}}$, the distribution of its separate contributions coming from the interactions of the given molecule with the ice phase and with the other adsorbate molecules, $U_{\mathrm{b}}^{\text {ice }}$ and $U_{\mathrm{b}}^{\text {lat }}$, respectively, have also been calculated. The binding energy distributions obtained for the adsorbed $\mathrm{CH}_{3} \mathrm{~F}, \mathrm{CH}_{2} \mathrm{~F}_{2}$ and $\mathrm{CHF}_{3}$ molecules in states MF1-MF5, MeF1-MeF5, and FF1-FF5, respectively, are shown in panels a, b, and c, respectively, of Figure 7.

The $P\left(U_{\mathrm{b}}^{\text {ice }}\right)$ distribution of $\mathrm{CH}_{3} \mathrm{~F}$ (Fig. 7.a) is unimodal in every case. In state $\mathrm{MF} 1$, corresponding to the lowest surface coverage, its peak is located at about $-30 \mathrm{~kJ} / \mathrm{mol}$, but with increasing surface coverage it shifts to about $-20 \mathrm{~kJ} / \mathrm{mol}$. Considering the fact that the energy of a C-H donated hydrogen bond is about $-10 \mathrm{~kJ} / \mathrm{mol},[! 65]$ the position of the $P\left(U_{\mathrm{b}}^{\text {ice }}\right)$ peak indicates that at very low surface coverage, when the adsorbed $\mathrm{CH}_{3} \mathrm{~F}$ molecules do not interact and do not compete for the positions with each other, the majority of the adsorbed molecules form three weak $\mathrm{C}-\mathrm{H}^{\cdots \cdots} \mathrm{O}$ type hydrogen bonds with the surface water molecules. Consistently, in state MF1 the $P\left(U_{\mathrm{b}}^{\text {lat }}\right)$ distribution has a sharp peak at zero energy, confirming that in this state the adsorbed molecules indeed do not interact with each other. At higher surface coverages, on the other hand, the adsorbed molecules form, on average, only two such hydrogen bonds due to the increasing competition of them for adsorbed positions. The fact that the $P\left(U_{\mathrm{b}}^{\text {ice }}\right)$ distributions are unimodal reflects the weakness of the $\mathrm{C}-\mathrm{H}^{\cdots \cdots} \mathrm{O}$ type hydrogen bonds, as peaks corresponding to $\mathrm{CH}_{3} \mathrm{~F}$ molecules forming $0,1,2$, and 3 such hydrogen bonds with the surface waters are too close to each other, and hence they merge to a single, broad peak. The broadness of this peak, in particular, in states MF2-MF5, in which $P\left(U_{\mathrm{b}}^{\text {ice }}\right)$ is noticeably different from zero in the entire energy range between about -40 and $0 \mathrm{~kJ} / \mathrm{mol}$, suggests that molecules forming $0,1,2$, and 3 hydrogen bonds with the surface waters all occur with non-negligible probabilities.

As it has already been noted, the $P\left(U_{\mathrm{b}}^{\text {lat }}\right)$ distribution of $\mathrm{CH}_{3} \mathrm{~F}$ (Fig. 7.a) has a sharp peak at zero energy in state MF1, due to the isolation of the adsorbed molecules from each other in this state. However, this distribution has also a small but noticeable shoulder around $-5 \mathrm{~kJ} / \mathrm{mol}$, reflecting the few dimers of adsorbed $\mathrm{CH}_{3} \mathrm{~F}$ (i.e., molecule pairs adsorbed in the 
vicinity of each other). With increasing surface coverage, the peak of the $P\left(U_{\mathrm{b}}^{\text {lat }}\right)$ distribution progressively shifts to lower energies, reflecting the simple fact that a larger number of adsorbed molecules corresponds to an increase of the lateral interaction, and hence to a deeper lateral binding energy.

In the case of $\mathrm{CH}_{2} \mathrm{~F}_{2}$, the $P\left(U_{\mathrm{b}}^{\text {ice }}\right)$ distribution (Fig. 7.b) is unimodal in states MeF1MeF3 of low surface coverages, and its peak is located in the energy range of $-40--50 \mathrm{~kJ} / \mathrm{mol}$. Considering that the energy of a strong, $\mathrm{O}-\mathrm{H}$ donated hydrogen bond is around -20$-25 \mathrm{~kJ} / \mathrm{mol}$, this finding indicates that the majority of the adsorbed $\mathrm{CH}_{2} \mathrm{~F}_{2}$ molecules form two hydrogen bonds with the surface waters. In states MeF1 and MeF2 the $P\left(U_{\mathrm{b}}^{\mathrm{ice}}\right)$ distribution extends to about $-70 \mathrm{~kJ} / \mathrm{mol}$, indicating that a few molecules - presumably those aligned in orientation $\mathrm{I}_{\mathrm{MeF}}$ - may even form three such hydrogen bonds. In states MeF4 and MeF5 the $P\left(U_{\mathrm{b}}^{\text {ice }}\right)$ distribution becomes bimodal, besides the peak around $-40 \mathrm{~kJ} / \mathrm{mol}$ another peak appears around $-10 \mathrm{~kJ} / \mathrm{mol}$. The position of this latter peak indicates that the molecules corresponding to it do not form any hydrogen bond with the surface water molecules. This finding helps us to resolve the seeming contradiction between the observed multilayer character of the adsorption at states that are close to the point of condensation, such as MeF4, as seen from the adsorption isotherm (see Fig. 3), and the lack of a second layer peak on the corresponding density profile (see Fig. 5). Thus, having all hydrogen bonding positions at the ice surface occupied by adsorbed $\mathrm{CH}_{2} \mathrm{~F}_{2}$ molecules, the ice surface is not yet fully covered, newly arriving adsorbates can still be accommodated in contact with the ice phase, however, without the possibility of forming hydrogen bonds with it. In other words, these molecules form a second layer in an energetic rather than a geometric sense. As is seen from the $P\left(U_{\mathrm{b}}^{\text {ice }}\right)$ distribution in the condensed state MeF5, once all the contact positions with the ice surface are occupied, the fraction of the double hydrogen bonded molecules (i.e., the ones forming the energetic first layer) and that of the non hydrogen bonded ones (forming the energetic second layer) are roughly equal to each other. This finding also explains the fact that the density peak of the first (geometric) layer in state MeF4 is much smaller than in the condensed state MeF5, i.e., when it is fully saturated (see Fig. 5), even if, according to the adsorption isotherm (Fig. 3) the first (energetic) layer is already saturated in state MeF4. 
The $P\left(U_{\mathrm{b}}^{\text {lat }}\right)$ distribution of $\mathrm{CH}_{2} \mathrm{~F}_{2}$, (Fig. 7.b) is bimodal in state MeF1, having a small peak around $-10 \mathrm{~kJ} / \mathrm{mol}$ besides the trivial peak of the isolated molecules at zero energy. In state MeF2 the distribution has its peaks at the same positions, only their heights, reflecting their relative importance is changed. This suggests that the $-10 \mathrm{~kJ} / \mathrm{mol}$ energy corresponding to the position of the first peak is likely the interaction energy of an adsorbed dimer of $\mathrm{CH}_{2} \mathrm{~F}_{2}$ molecules. This energy is surprisingly low, being about twice as low as the same dimer energy of $\mathrm{CH}_{3} \mathrm{~F}$ and $\mathrm{CHF}_{3}$, and also about twice as low as what was previously found for $\mathrm{CH}_{2} \mathrm{~F}_{2}$ using the JM potential model. [!19] With increasing surface coverage, the zero energy peak of $P\left(U_{\mathrm{b}}^{\text {lat }}\right)$ rapidly vanishes (although it is still noticeable in state MeF4), and the other peak progressively shifts to lower energy values. Although its position is around $-25 \mathrm{~kJ} / \mathrm{mol}$ in state MeF4 (when even the first geometric layer is far from being saturated), it shifts down to about $-65 \mathrm{~kJ} / \mathrm{mol}$, and the distribution extends down to about $-100 \mathrm{~kJ} / \mathrm{mol}$ in state MeF5. Considering the fact that the position of this peak reflects the cohesion in the liquid phase, this finding is rather surprising, as this energy is again twice as deep as for $\mathrm{CH}_{3} \mathrm{~F}$ and $\mathrm{CHF}_{3}$ as well as even for the $\mathrm{JM}$ model of $\mathrm{CH}_{2} \mathrm{~F}_{2}$, [!19] and is comparable with that of hydrogen bonding liquids. $[! 24,46,47]$

In the case of $\mathrm{CHF}_{3}$, the $P\left(U_{\mathrm{b}}^{\text {ice }}\right)$ distribution (Fig. 7.c) is unimodal, located around the $U_{\mathrm{b}}^{\text {ice }}$ value of about-30 kJ/mol in states FF1 and FF2, and becomes bimodal, developing a second peak above $-10 \mathrm{~kJ} / \mathrm{mol}$ in states of higher surface coverages. This finding indicates that even isolated $\mathrm{CHF}_{3}$ molecules do not form more than one hydrogen bonds with the surface waters, even if their preferred surface alignments would allow the formation of two or three such hydrogen bonds (see Fig. 6.c and the corresponding discussion). Also, similarly to $\mathrm{CH}_{2} \mathrm{~F}_{2}$, once the hydrogen bonding positions at the ice surface are all occupied, a second layer, in an energetic sense, is formed still in contact with the ice phase. The $P\left(U_{\mathrm{b}}^{\text {lat }}\right)$ distributions in states FF1 and FF2 are characterized by the large trivial peak of the isolated molecules at zero energy, and a shoulder, corresponding to the adsorbed dimers, around $-5 \mathrm{~kJ} / \mathrm{mol}$. With increasing surface coverages the zero energy peak vanishes, and the other peak progressively shifts to lower energies, being around $-30 \mathrm{~kJ} / \mathrm{mol}$ in the condensed state of FF5. 
The distributions of the total binding energy, $P\left(U_{\mathrm{b}}\right)$, coincides roughly with $P\left(U_{\mathrm{b}}^{\text {ice }}\right)$ in the lowest surface coverage states, when the $P\left(U_{\mathrm{b}}^{\text {lat }}\right)$ distribution is dominated by the zero energy peak, as in such cases practically the entire binding energy comes from the interaction with the ice phase. With increasing surface coverages, the $P\left(U_{\mathrm{b}}\right)$ distribution progressively shifts to lower energies in every case, indicating that the increasing lateral interaction between the adsorbed molecules clearly overcompensates the weakening of their interaction with the ice phase due to their increasing competition in every case.

\section{Discussion and Summary}

In this paper, we presented a detailed analysis of the adsorption of various fluorinated methane derivatives, described by the general chemical formula of $\mathrm{CH}_{n} \mathrm{~F}_{4-n}$, at the surface of $\mathrm{I}_{h}$ ice under tropospheric conditions. The behavior of the adsorbate molecules having a net dipole moment (i.e., $\mathrm{CH}_{3} \mathrm{~F}, \mathrm{CH}_{2} \mathrm{~F}_{2}$ and $\mathrm{CHF}_{3}$ ) turned out to be markedly different from that of the tetrahedral, apolar molecules, i.e., $\mathrm{CH}_{4}$ and $\mathrm{CF}_{4}$. These latter molecules, having their critical point close to, or even below the simulation temperature of $200 \mathrm{~K}$, form a dense vapor or gas phase at low chemical potential values, thus, the number of molecules being adsorbed at the ice surface and that being in the vapor/gas phase are comparable with each other. The calculation of the surface excess revealed that these molecules adsorb rather weakly at the polar ice surface, in a good agreement with experimental observations $[! 13,66]$.

The partially fluorinated methane derivatives, on the other hand, exhibit multilayer adsorption. The adsorbed molecules are stabilized by various different hydrogen bonding schemes at the ice surface. Thus, $\mathrm{CH}_{3} \mathrm{~F}$ forms several weak, $\mathrm{C}-\mathrm{H}^{\cdots \cdots} \mathrm{O}$ type hydrogen bonds with surface waters, the mean number of such hydrogen bonds per adsorbate being close to 2 even when the first layer is saturated. Clearly, the possibility of multiple hydrogen bond formation overcompensates here the relative weakness of the $\mathrm{C}-\mathrm{H}$ donated hydrogen bonds. $\mathrm{CH}_{2} \mathrm{~F}_{2}$ and $\mathrm{CHF}_{3}$, on the other hand, forms strong, $\mathrm{O}-\mathrm{H}$ donated $\mathrm{O}-\mathrm{H}^{\cdots \cdots} \mathrm{F}$ type hydrogen bonds with the surface waters, the number of such hydrogen bonds per adsorbate molecule being 2 for $\mathrm{CH} 2 \mathrm{~F} 2$ and 1 for $\mathrm{CHF}_{3}$. For these adsorbates, the saturation of the hydrogen bonding positions does not coincide with the full coverage of the ice surface, instead, the ice surface can host also non 
hydrogen bonded adsorbate molecules in a quantity that is comparable with that of the hydrogen bonded ones. Thus, these non hydrogen bonded contact molecules form a second layer in terms of adsorption energy, while in a geometric sense they are still part of the first molecular layer. It is also clear that for these molecules, having less $\mathrm{H}$ and more $\mathrm{F}$ atoms than $\mathrm{CH}_{3} \mathrm{~F}$, the formation of a fewer but stronger $\mathrm{O}-\mathrm{H}$ donated hydrogen bonds proved to be advantageous over the formation of weak, $\mathrm{C}-\mathrm{H}$ donated hydrogen bonds, as the number of this latter type of hydrogen bonds they can form is not enough to compensate their relative weakness.

The fact that recently we performed a similar study of the adsorption of $\mathrm{CH}_{2} \mathrm{~F}_{2}$ on ice, [!19] but using a different potential model [!53] allows us now to address the force field dependence of the results. In a qualitative sense both studies led to similar conclusions, however, there are strong differences in their details. Thus, both studies revealed multilayer adsorption, however, the multilayer character turned out to be much stronger using the JM model than in the present study. In both cases, orientations $\mathrm{I}_{\mathrm{MeF}}$ and $\mathrm{II}_{\mathrm{MeF}}$ turned out to be preferred at the ice surface, however, their relative strengths are rather different as obtained with the two potential models. The $\langle N\rangle(\mu)$ adsorption isotherm is found here to be shifted to about $20 \mathrm{~kJ} / \mathrm{mol}$ lower chemical potential values with respect to what was obtained with the JM model (see Fig. 1 of this paper and Fig. 1 of Ref. [!19]). Further, the lateral binding energy distributions were also found at considerably lower energies in the present study than in that with the JM model.

The vast majority of these differences can be traced back to the different strength of the $\mathrm{CH}_{2} \mathrm{~F}_{2}-\mathrm{CH}_{2} \mathrm{~F}_{2}$ interaction with the two models. Clearly, the adsorption behavior is always the result of the interplay between adhesive and cohesive forces, i.e., that of the adsorbateadsorbent and adsorbate-adsorbate interactions. Too strong lateral interactions, i.e., the dominance of cohesion over adhesion leads to condensation of the adsorbate before the formation of a more or less saturated adsorption layer can occur, while the opposite situation leads to a monolayer that is stable in a broad range of chemical potentials. The comparison of the two sets of results show that the Palmer-Anchell model exhibits much stronger cohesion, i.e., $\mathrm{CH}_{2} \mathrm{~F}_{2}-\mathrm{CH}_{2} \mathrm{~F}_{2}$ attraction than the $\mathrm{JM}$ model. This difference is reflected in the aforementioned shift of the adsorption isotherm as well as of the binding energy distribution, the considerably deeper interaction energy of the adsorbed dimers (see sec. 3.3), and even in 
the weaker multilayer character of the adsorption, as the possible formation and building up of the outer molecular layers is preceded here by the condensation of $\mathrm{CH}_{2} \mathrm{~F}_{2}$.

There are several points that suggest that in this respect the JM model performs considerably better than the Palmer-Anchell one. First, all the energy-related values (i.e., mean binding energy in a condensed system, energy of the adsorbed dimer, chemical potential of condensation) obtained with the JM model are comparable with the similar values obtained for $\mathrm{CH}_{3} \mathrm{~F}$ and $\mathrm{CHF}_{3}$, while those obtained with the Palmer-Anchell model are much deeper. One can expect similar values for adsorbates of such a large chemical similarity; however, the values obtained with the Palmer-Anchell model are in the order of those obtained previously for various hydrogen bonding adsorbates. [!21,22,24,46,47] Second, the Palmer-Anchell model seems to seriously underestimate the melting point of $\mathrm{CH}_{2} \mathrm{~F}_{2}$ (see sec. 3.2), which can well be another sign of the inaccurate description of the cohesive forces. Finally, and most importantly, the JM model was parameterized to reproduce the bulk liquid phase properties of $\mathrm{CH}_{2} \mathrm{~F}_{2}$ in the temperature range of about $150-220 \mathrm{~K},[! 53]$ and thus it is expected to account accurately for the cohesion of the system, while the Palmer-Anchell model was parameterized considering the properties of the isolated $\mathrm{CH}_{2} \mathrm{~F}_{2}$ dimer, and its performance is tested in simulations performed at $298 \mathrm{~K}$. [!49] Thus, it is not granted that the Palmer-Anchell model of $\mathrm{CH}_{2} \mathrm{~F}_{2}$ accounts well for the collective interaction in a condensed phase, in particular, at low temperature, which is responsible for cohesion. Furthermore, as it was recently shown by Malaspina et al. on the example of water, [!67] the energy scale in simple models is not necessarily correct over an extended temperature range, therefore, even if this model provides reasonable results at room temperature, it might well fail at the tropospheric temperature of $200 \mathrm{~K}$. This conclusion is well supported by the fact that while the JM model captures well the experimental values of the potential energy and density of liquid $\mathrm{CH}_{2} \mathrm{~F}_{2}$ at low temperature (i.e., $-18.03 \mathrm{~kJ} / \mathrm{mol}$ and $1.215 \mathrm{~g} / \mathrm{cm}^{3}$, respectively, at $221.5 \mathrm{~K}$, see Table 2 of Ref. [!53]), the Palmer-Anchell model seriously overestimates the magnitude of both (see Table 4). For these reasons, we think that our previous results on the adsorption of $\mathrm{CH}_{2} \mathrm{~F}_{2}$, [!19] obtained using the JM model [!53] of $\mathrm{CH}_{2} \mathrm{~F}_{2}$ are more reliable than the present ones whenever they differ substantially.

From a more general, atmospheric point of view, many HFC species are long lived greenhouses gases that are suspected to play an increasing role on climate change and atmospheric chemistry. It is thus of fundamental importance to better know their potential 
atmospheric sinks in order to better estimate their partitioning in the atmosphere. The present results show that the partially fluorinated methane derivatives may stick to the ice surface at low temperatures typical of the upper troposphere/lower stratosphere, and thus, ice particles of cirrus clouds may retain significant fractions of such molecules. In the same way, the large density areas of snowpack may enhance their partitioning values in the coldest zones of the Arctic boundary layer, as it was already suggested previously for trifluoroethanol. [!9]

Another potentially important finding, being in agreement with former IR spectroscopy results [!11] is that, at submonolayer coverage, at least one of the fluorine atoms of these molecules is pointing (more or less) towards the gas phase, which makes it easily accessible for further reactions with gas phase species or releasable upon photodissociation processes. Similar conclusion has also been suggested recently for partially chlorinated and brominated methane derivatives at the ice surface, on the basis of molecular dynamics calculations at low temperature. [!16]

To conclude, the present results, together with those of recent studies $[! 9,16,19]$ show that taking adsorption processes on atmospheric ice into account seems to be of great importance for achieving a better quantification of both the HFC scavenging (and thus their atmospheric lifetime) and the release of HFC photoproducts in cirrus clouds and snow.

Supporting Information. Numerical data of the adsorption isotherms obtained, and carbon-carbon radial distribution function of the adsorbate models in their neat bulk fluid phase at $200 \mathrm{~K}$.

\section{Acknowledgements}

This project is supported by the Hungarian OTKA Foundation under project No. 119732, by the Hungarian-French Intergovernmental Science and Technology Program (BALATON) under project No. TéT_15_FR-1-2016-0056, and by CNRS in the framework of an international program for scientific cooperation (PICS). 


\section{References}

(1) Solomon, S.; Garcia, R. R.; Rowland, F. S.; Wuebbles, D. J. On the Depletion of Antarctic Ozone, Nature 1986, 321, 755-758.

(2) Lei, Y. D.; Wania, F. Is Rain or Snow a More Efficient Scavenger of Organic Chemicals? Atmos. Environ. 2004, 38, 3557-3571.

(3) Abbatt, J. P. D.; Thomas, J. L.; Abrahamsson, K.; Boxe, C.; Granfors, A.; Jones, A. E.; King, M. D.; Saiz-Lopez, A.; Shepson, P. B.; Sodeau, J.; et al. Halogen Activation via Interactions with Environmental Ice and Snow in the Polar Lower Troposphere and Other Régions. Atmos. Chem. Phys. 2012, 12, 6237-6271.

(4) IPCC/TEAP (2005) Special Report: Safeguarding the Ozone Layer and the Global Climate System: Issues Related to Hydrofluorocarbons and Perfluorocarbons (Cambridge University Press, UK).

(5) UNEP (2007) 2006 Report of the Refrigeration, Air Conditioning and Heat Pumps Technical Options Committee (United Nations Environment Programme, Nairobi, Kenya)

(6) Hurwitz, M. M.; Fleming, E. L.; Newman, P. A.; Li, F.; Mlawer, E.; Cady-Pereira, K.; Bailey, R. Ozone Depletion by Hydrofluorocarbons. Geophys. Res. Lett. 2015, 42, 8686-8692.

(7) Velders, G. J. M.; Fahey, D. W.; Daniel, J. S.; McFarland, M.; Andersen, O. The Large Contribution of Projected HFC Emissions to Future Climate Forcing. Proc. Natl. Acad. Sci. USA 2009, 106, 10949-10954.

(8) Hossaini, R.; Chipperfield, M. P.; Montzka, S. A.; Rap, A.; Dhomse, S.; Feng, W. Efficiency of short-lived halogens at influencing climate through depletion of stratospheric ozone. Nature Geoscience 2015, 8, 186-190.

(9) Moreno, E.; Aranda, A.; Díaz-de-Mera, Y.; Martínez E.; Bravo, I.; Rodríguez, A. The Role of Tropospheric Ice Surfaces in the Elimination of the CFC Substitute, Trifluoroethanol. Phys. Chem. Chem. Phys. 2012, 14, 4425-4432.

(10) Buch, V.; Delzeit, L.; Blackledge, C.; Devlin, J. P. Structure of the Ice Nanocrystal Surface from Simulated versus Experimental Spectra of Adsorbed $\mathrm{CF}_{4}$. J. Phys. Chem. 1996, 100, 3732-3744. 
(11) Holmes, N. S.; Sodeau, J. R. A Study of the Interaction between Halomethanes and Water-Ice. J. Phys. Chem. A 1999, 103, 4673-4679.

(12) Graham, A. P.; Menzel, A.; Toennies, J. P. Adsorption of Fluoroform $\mathrm{CHF}_{3}$ on Ice $\mathrm{I}_{\mathrm{h}}(0001)$ : Structure and Vibrations. J. Chem. Phys. 1999, 111, 1169-1174.

(13) Martin, C.; Manca, C.; Roubin, P. Adsorption of Small Molecules on Amorphous Ice: Volumetric and FT-IR Isotherm Co-measurements. Surf. Sci. 2002, 502-503, 275-279.

(14) Pártay, L. B.; Jedlovszky, P.; Hoang, P. N. M.; Picaud, S.; Mezei, M. Free-Energy Profile of Small Solute Molecules at the Free Surfaces of Water and Ice, as Determined by Cavity Insertion Widom Calculations. J. Phys. Chem. C 2007, 111, 9407-9416.

(15) Habartová, A.; Valsaraj, K. T.; Roeselová, M. Molecular Dynamics Simulations of Small Halogenated Organics at the Air-Water Interface: Implications in Water Treatment and Atmospheric Chemistry. J. Phys. Chem. A 2013, 1176, 9205-9215.

(16) Habartová, A.; Hormain, L.; Pluhařová, E.; Briquez, S.; Monnerville, M.; Toubin, C.; Roeselová, M. Molecular Simulations of Halomethanes at the Air/Ice Interface. J. Phys. Chem. A 2015, 119, 10052-10059.

(17) Adams, D. J. Grand Canonical Ensemble Monte Carlo for a Lennard-Jones Fluid. Mol. Phys. 1975, 29, 307-311.

(18) Allen, M. P.; Tildesley, D. J. Computer Simulation of Liquids; Clarendon: Oxford, 1987.

(19) Sumi, I.; Picaud, S.; Jedlovszky, P. Adsorption of Methylene Fluoride and Methylene Chloride at the Surface of Ice under Tropospheric Conditions. A Grand Canonical Monte Carlo Simulation Study. J. Phys. Chem. C 2015, 119, 17243-17252.

(20) Jedlovszky, P.; Partay, L.; Hoang, P. N. M.; Picaud, S.; von Hessberg, P.; Crowley, J. N. Determination of the Adsorption Isotherm of Methanol on the Surface of Ice. An Experimental and Grand Canonical Monte Carlo Simulation Study. J. Am. Chem. Soc. 2006, 128, 15300-15309.

(21) Petitjean, M.; Hantal, Gy.; Chauvin, C.; Mirabel, P.; Le Calvé, S.; Hoang, P. N. M.; Picaud, S.; Jedlovszky, P. Adsorption of Benzaldehyde at the Surface of Ice, Studied by Experimental Method And Computer Simulation. Langmuir 2010, 26, 9596-9606. 
(22) Darvas, M.; Lasne, J.; Laffon, C.; Parent, P.; Picaud, S.; Jedlovszky, P. Adsorption of Acetaldehyde on Ice as Seen From Computer Simulation and Infrared Spectroscopy Measurements. Langmuir 2012, 28, 4198-4207.

(23) Mészár, Zs. E.; Hantal, Gy.; Picaud, S.; Jedlovszky, P. Adsorption of Aromatic Hydrocarbon Molecules at the Surface of Ice, As Seen by Grand Canonical Monte Carlo Simulation. J. Phys. Chem. C 2013, 117, 6719-6729.

(24) Picaud, S.; Jedlovszky, P. Adsorption of $\mathrm{H}_{2} \mathrm{O}_{2}$ at the Surface of $\mathrm{I}_{\mathrm{h}}$ Ice, as Seen from Grand Canonical Monte Carlo Simulations. Chem. Phys. Letters 2014, 600, 73-78.

(25) Puibasset, J.; Pellenq, R. J. M. Water Adsorption on Hydrophilic Mesoporous and Place Silica Substrates: a Grand Canonical Monte Carlo Simulation Study. J. Chem. Phys. 2003, $118,5613-5622$.

(26) Daub, C. D.; Patey G. N.; Jack, D. B.; Sallabi A. K. Monte Carlo Simulations of the Adsorption of $\mathrm{CO}_{2}$ on the $\mathrm{MgO}(100)$ Surface. J. Chem. Phys. 2006, 124, 114706-1-9.

(27) Tombácz, E.; Hajdú, A.; Illés, E.; László, K.; Garberoglio, G.; Jedlovszky, P. Water in Contact with Magnetite Nanoparticles, as Seen from Experiments and Computer Simulations. Langmuir 2009, 25, 13007-13014.

(28) Rutkai, G.; Kristóf, T. Molecular Simulation Study of Intercalation of Small Molecules in Kaolinite. Chem. Phys. Letters 2008, 462, 269-274.

(29) Croteau, T.; Bertram, A. K.; Patey, G. N. Adsorption and Structure of Water on Kaolinite Surfaces: Possible Insight into Ice Nucleation from Grand Canonical Monte Carlo Calculations. J. Phys. Chem. A 2008, 112, 10708-10712.

(30) Jameson, C. J.; Jameson, K.; Baello, B. I.; Lim, H. M. Grand Canonical Monte Carlo Simulations of the Distribution and Chemical Shifts of Xenon in the Cages of Zeolite NaA. 1. Distribution and Xe-129 Chemical Shifts. J. Chem. Phys. 1994, 100, $5965-$ 5976.

(31) Smit, B. Grand Canonical Monte Carlo Simulations of Chain Molecules: Adsorption Isotherms of Alkanes in Zeolites. Mol. Phys. 1995, 85, 153-172.

(32) Pellenq, R. J. M.; Tavitian, B.; Espinat, D.; Fuchs, A. H. Grand Canonical Monte Carlo Simulations of Adsorption of Polar and Nonpolar Molecules in NaY Zeolite. Langmuir 1996, 12, 4768-4783. 
(33) Macedonia, M. D.; Maginn, E. J. Pure and Binary Component Sorption Equilibria of Light Hydrocarbons in the Zeolite Silicalite from Grand Canonical Monte Carlo Simulations. Fluid Phase Equil. 1999, 158-160, 19-27.

(34) Rutkai, G.; Csányi, É.; Kristóf, T. Prediction of Adsorption Equilibria of WaterMethanol Mixtures in Zeolite NaA by Molecular Simulation. Mol. Simul. 2006, 32, 869-875.

(35) Kristóf, T.; Csányi, É.; Rutkai, G. Prediction of Adsorption and Separation of WaterAlcohol Mixtures with Zeolite NaA. Microporous Mesoporous Mat. 2008, 114, 455464.

(36) Resat, H.; Mezei, M. Grand Canonical Monte Carlo Simulation of Water Positions in Crystal Hydrates. J. Am. Chem. Soc. 1994, 116, 7451-7452.

(37) Jung, D. H.; Kim, D.; Lee, T. B.; Choi, S. B.; Yoon, J. H.; Kim, J.; Choi, K.; Choi, S. H. Grand Canonical Monte Carlo Simulation Study on the Catenation Effect on Hydrogen Adsorption onto the Interpenetrating Metal-Organic Frameworks. J. Phys. Chem. B 2006, 110, 22987-22990.

(38) Garberoglio, G. Computer Simulation of the Adsorption of Light Gases in Covalent Organic Frameworks. Langmuir 2007, 23, 12154-12158.

(39) Ramsahye, N. A.; Maurin, G.; Bourelly, S.; Llewellyn, P. L.; Devic, T.; Serre, C.; Loiseau, T.; Ferey, G. Adsorption of $\mathrm{CO}_{2}$ in Metal Organic Frameworks of Different Metal Centres: Grand Canonical Monte Carlo Simulations Compared to Experiments. Adsorption 2007, 13, 461-467.

(40) Samios, S.; Stubos, A. K.; Kanellopoulos, N. K.; Cracknell, R. F.; Papadopoulos, G. K.; Nicholson, D. Determination of Micropore Size Distribution from Grand Canonical Monte Carlo Simulations and Experimental $\mathrm{CO}_{2}$ Isotherm Data. Langmuir 1997, 13, 2795-2802.

(41) Challa, S. R.; Sholl, D. S.; Johnson, J. K. Adsorption and Separation of Hydrogen Isotopes in Carbon Nanotubes: Multicomponent Grand Canonical Monte Carlo Simulations. J. Chem. Phys. 2002, 116, 814-824.

(42) Striolo, A.; Chialvo, A. A.; Gubbins, K. E.; Cummings, P. T. Water in Carbon Nanotubes: Adsorption Isotherms and Thermodynamic Properties from Molecular Simulation. J. Chem. Phys. 2005, 122, 234712-1-14. 
(43) Moulin, F.; Picaud, S.; Hoang, P. N. M.; Jedlovszky, P. Grand Canonical Monte Carlo Simulation of the Adsorption Isotherms of Water Molecules on a Model Soot Particle $J$. Chem. Phys. 2007, 127, 164719-1-11.

(44) Hantal, Gy.; Picaud, S.; Hoang, P. N. M.; Voloshin, V. P.; Medvedev, N. N.; Jedlovszky, P. Water Adsorption Isotherms on Porous Onionlike Carbonaceous Particles. Simulations with the Grand Canonical Monte Carlo Method. J. Chem. Phys. 2010, 133, 144702-1-12.

(45) Firlej, L. ; Kuchta, B. ; Lazarewicz, A. ; Pfeifer, P. Increased $\mathrm{H}_{2}$ Gravimetric Storage Capacity in Truncated Carbon Slit Pores Modeled by Grand Canonical Monte Carlo. Carbon 2013, 53, 208-215.

(46) Szőri, M.; Jedlovszky, P.; Roeselová, M. Water Adsorption on Hydrophilic and Hydrophobic Self-Assembled Monolayers as Proxies For Atmospheric Surfaces. A Grand Canonical Monte Carlo Simulation Study. Phys. Chem. Chem. Phys. 2010, 12, 4604-4616.

(47) Szőri, M.; Roeselová, M.; Jedlovszky, P. Surface Hydrophilicity-Dependent Water Adsoprtion on Mixed Self-Assembled Monolayers of $\mathrm{C}_{7}-\mathrm{CH}_{3}$ and $\mathrm{C}_{7}-\mathrm{COOH}$ residues. A Grand Canonical Monte Carlo Simulation Study. J. Phys. Chem. C 2011, 115, 19165-19177.

(48) CRC Handbook of Chemistry and Physics; Lide, D. R.; Ed.; CRC Press: Boca Raton, 1997-1998.

(49) Palmer, B. J.; Anchell, J. L. Molecular Mechanics Parameters for Fluorine-Substituted methanes from ab Initio Quantum Calculations. J. Phys. Chem. 1995, 99, 12239-12248.

(50) Mahoney, M.; Jorgensen, W. L. A Five-Site Model for Liquid Water and the Reproduction of The Density Anomaly by Rigid, Nonpolarizable Potential Functions. $J$. Chem. Phys. 2000, 112, 8910-8922.

(51) Nada, H.; van der Eerden, J. P. M. J. An Intermolecular Potential Model for the Simulation of Ice and Water near the Melting Point: A Six-Site Model of $\mathrm{H}_{2} \mathrm{O} . J$. Chem. Phys. 2003, 118, 7401-7413.

(52) Vega, C.; Sanz, E.; Abascal, J. L. F. The Melting Temperature of the Most Common Models of Water. J. Chem. Phys. 2005, 122, 114507-1-9. 
(53) Jedlovszky, P.; Mezei, M. Computer Simulation Study of Liquid $\mathrm{CH}_{2} \mathrm{~F}_{2}$ with a New Effective Pair Potential Model. J. Chem. Phys. 1999, 110, 2991-3002.

(54) Hess, B.; Kutzner, C.; van der Spoel, D.; Lindahl, E. GROMACS 4: Algorithms for Highly Efficient, Load-Balanced, and Scalable Molecular Simulation. J. Chem. Theory Comput. 2008, 4, 435-447.

(55) Mezei, M. MMC: Monte Carlo Program for Simulation of Molecular Assemblies. URL: http://inka.mssm.edu/ mezei/mmc.

(56) Metropolis, N.; Rosenbluth, A. W.; Rosenbluth, M. N.; Teller, A. H.; Teller, E. Equation of State Calculations by Fast Computing Machines J. Chem. Phys. 1953, 21 1087-1093.

(57) Mezei, M. A Cavity-Biased ( T, V, $\mu$ ) Monte Carlo Method for the ComputerSimulation of Fluids. Mol. Phys. 1980, 40, 901-906.

(58) Mezei, M. Grand Canonical Ensemble Monte Carlo Study of Dense Liquid LennardJones, Soft Spheres and Water. Mol. Phys. 1987, 61, 565-582. Erratum: 1989, 67, $1207-$ 1208.

(59) Everett, D. H. Manual of Symbols Terminology for Physicochemical Quantities and Units, Appendix II: Definitions, Terminology and Symbols in Colloid and Surface Chemistry. Pure Appl. Chem. 1972, 31, 577-638.

(60) Mitropoulos, A. C. What is a Surface Excess? J. Eng. Science Technol. Review 2008, 1, $1-3$.

(61) Langmuir, I. The Constitution and Fundamental Properties of Solids and Liquids. Part I: Solids. J. Am. Chem. Soc. 1916, 38, 2221-2295.

(62) Shaw, D. J. Introduction to Colloid and Surface Chemistry, Butterworths: London, 1980.

(63) Jedlovszky, P.; Vincze, Á.; Horvai, G. New Insight into the Orientational Order of Water Molecules at the Water/1,2-Dichloroethane Interface: A Monte Carlo Simulation Study. J. Chem. Phys. 2002, 117, 2271-2280.

(64) Jedlovszky, P.; Vincze, Á.; Horvai, G. Full Description of the Orientational Statistics of Molecules Near to Interfaces. Water at the Interface with $\mathrm{CCl}_{4}$. Phys. Chem. Chem. Phys. 2004, 6, 1874-1879. 
(65) Jedlovszky, P.; Turi, L. Role of the $\mathrm{C}-\mathrm{H}^{\cdots \cdots} \mathrm{O}$ Hydrogen Bonds in Liquids: A Monte Carlo Simulation Study of Liquid Formic Acid Using a Newly Developed PairPotential. J. Phys. Chem. B. 1997, 101, 5429-5439; Erratum: J. Phys. Chem. B. 1999, 103, 3510-3510.

(66) Manca, C.; Roubin, P.; Martin, C.; Volumetric and Infrared Co-Measurements of $\mathrm{CH}_{4}$ and CO isotherms on microporous ice. Chem. Phys. Lett. 2000, 330, 21-26.

(67) Malaspina, D. C.; Bermúdez di Lorenzo, A. J.; Pereyra, R. G.; Szleifer, I.; Carignano, M. A. The Water Supercooled Regime as Described by Four Common Water Models. J. Chem. Phys. 2013, 139, 024506-1-8. 


\section{Tables}

Table 1. Physical Characteristics of the Adsorbates Considered ${ }^{\text {a }}$

\begin{tabular}{ccccc}
\hline \hline Compound & $\begin{array}{c}\text { Dipole } \\
\text { moment }(\mathrm{D})\end{array}$ & $\begin{array}{c}\text { Melting } \\
\text { temperature }(\mathrm{K})\end{array}$ & $\begin{array}{c}\text { Boiling } \\
\text { temperature }(\mathrm{K})\end{array}$ & $\begin{array}{c}\text { Critical } \\
\text { temperature }(\mathrm{K})\end{array}$ \\
\hline $\mathrm{CH}_{4}$ & 0 & 90.8 & 111.6 & 190.6 \\
$\mathrm{CH}_{3} \mathrm{~F}$ & 2.37 & 131.4 & 194.8 & 317.9 \\
$\mathrm{CH}_{2} \mathrm{~F}_{2}$ & 2.27 & 137.2 & 221.5 & 351.7 \\
$\mathrm{CHF}_{3}$ & 2.02 & 118.0 & 191.1 & 299.4 \\
$\mathrm{CF}_{4}$ & 0 & 89.6 & 145.1 & 227.7 \\
\hline a Data taken from Ref. $[! 48]$ & & & & \\
\hline
\end{tabular}

${ }^{\mathrm{a}}$ Data taken from Ref. [!48] $\quad{ }^{\mathrm{b}}$ Values corresponding to the molecular models used 
Table 2. Interaction Parameters of the Molecular Models Used

\begin{tabular}{|c|c|c|c|c|}
\hline Molecule & Site & $\sigma / \AA$ & $\varepsilon / \mathrm{kJ} \mathrm{mol}^{-1}$ & $q / \mathrm{e}$ \\
\hline \multirow{2}{*}{$\mathrm{CH}_{4}{ }^{\mathrm{a}}$} & $\mathrm{C}$ & 3.200 & 1.0467 & -0.416 \\
\hline & $\mathrm{H}$ & 2.625 & 0.0230 & 0.104 \\
\hline \multirow{3}{*}{$\mathrm{CH}_{3} \mathrm{~F}^{\mathrm{a}}$} & $\mathrm{C}$ & 3.910 & 0.1294 & 0.339 \\
\hline & $\mathrm{H}$ & 2.311 & 0.0758 & -0.003 \\
\hline & $\mathrm{F}$ & 2.360 & 1.9134 & -0.330 \\
\hline \multirow{3}{*}{$\mathrm{CH}_{2} \mathrm{~F}_{2}^{\mathrm{a}}$} & $\mathrm{C}$ & 2.628 & 3.4122 & 0.050 \\
\hline & $\mathrm{H}$ & - & - & 0.155 \\
\hline & $\mathrm{F}$ & 2.809 & 0.5192 & -0.180 \\
\hline \multirow{3}{*}{$\mathrm{CHF}_{3}{ }^{\mathrm{a}}$} & $\mathrm{C}$ & 3.158 & 2.2567 & 0.651 \\
\hline & $\mathrm{H}$ & - & - & 0.048 \\
\hline & $\mathrm{F}$ & 3.116 & 0.1432 & -0.233 \\
\hline \multirow{2}{*}{$\mathrm{CF}_{4}{ }^{\mathrm{a}}$} & $\mathrm{C}$ & 4.505 & 0.0720 & 0.716 \\
\hline & $\mathrm{F}$ & 2.773 & 0.4517 & -0.179 \\
\hline \multirow{3}{*}{ water $^{b}$} & $\mathrm{O}$ & 3.120 & 0.6699 & 0.000 \\
\hline & $\mathrm{H}$ & - & - & 0.241 \\
\hline & $\mathrm{L}^{\mathrm{c}}$ & - & - & -0.241 \\
\hline
\end{tabular}


Table 3. Geometry Parameters of the Potential Models Used

\begin{tabular}{|c|c|c|c|c|}
\hline molecule & bond & bond length $(\AA)$ & angle & bond angle (deg) \\
\hline \multirow{3}{*}{$\mathrm{CH}_{4}$} & $\mathrm{C}-\mathrm{H}$ & 1.086 & & \\
\hline & & & $\mathrm{H}-\mathrm{C}-\mathrm{H}$ & 109.47 \\
\hline & $\mathrm{C}-\mathrm{H}$ & 1.090 & & \\
\hline \multirow[t]{3}{*}{$\mathrm{CH}_{3} \mathrm{~F}$} & $\mathrm{C}-\mathrm{F}$ & 1.407 & & \\
\hline & & & $\mathrm{H}-\mathrm{C}-\mathrm{F}$ & 108.05 \\
\hline & $\mathrm{C}-\mathrm{H}$ & 1.089 & & \\
\hline \multirow{3}{*}{$\mathrm{CH}_{2} \mathrm{~F}_{2}$} & $\mathrm{C}-\mathrm{F}$ & 1.375 & & \\
\hline & & & $\mathrm{H}-\mathrm{C}-\mathrm{H}$ & 114.48 \\
\hline & & & F-C-F & 108.42 \\
\hline \multirow{3}{*}{$\mathrm{CHF}_{3}$} & $\mathrm{C}-\mathrm{H}$ & 1.088 & & \\
\hline & $\mathrm{C}-\mathrm{F}$ & 1.351 & & \\
\hline & & & H-C-F & 110.58 \\
\hline \multirow{2}{*}{$\mathrm{CF} 4$} & $\mathrm{C}-\mathrm{F}$ & 1.335 & & \\
\hline & & & F-C-F & 109.47 \\
\hline \multirow{4}{*}{$\mathrm{H}_{2} \mathrm{O}$} & $\mathrm{O}-\mathrm{H}$ & 0.957 & & \\
\hline & $\mathrm{O}-\mathrm{L}$ & 0.700 & & \\
\hline & & & $\mathrm{H}-\mathrm{O}-\mathrm{H}$ & 104.50 \\
\hline & & & L-O-L & 110.70 \\
\hline
\end{tabular}


Table 4. Fluid Phase Properties of the Adsorbate Models Used, As Obtained from Molecular Dynamics Simulations at $200 \mathrm{~K}$. Values in Parentheses Correspond to the Jedlovszky-Mezei Model (Ref. [!53]) of $\mathrm{CH}_{2} \mathrm{~F}_{2}$.

\begin{tabular}{cccccc}
\hline \hline & $\mathrm{CH}_{4}$ & $\mathrm{CH}_{3} \mathrm{~F}$ & $\mathrm{CH}_{2} \mathrm{~F}_{2}$ & $\mathrm{CHF}_{3}$ & $\mathrm{CF}_{4}$ \\
\hline$D / \mathrm{nm}^{2} \mathrm{ps}^{-1}$ & 11.6 & $4.23 \times 10^{-3}$ & $1.87 \times 10^{-4}$ & $1.56 \times 10^{-3}$ & $4.51 \times 10^{-3}$ \\
& & & $\left(2.95 \times 10^{-3}\right)$ & & \\
$\rho / \mathrm{g} \mathrm{cm}^{-3}$ & $1.07 \times 10^{-3}$ & 0.92 & $2.18(1.28)$ & 1.65 & 1.32 \\
$\mathrm{U} / \mathrm{kJ} \mathrm{mol}^{-1}$ & $-1.76 \times 10^{-2}$ & -16.06 & $-47.40(-17.85)$ & -22.01 & -9.63 \\
\hline \hline
\end{tabular}




\section{Figure Legend}

Figure 1. Number of adsorbate molecules in the basic simulation box as a function of their chemical potential, as obtained from our simulations. $\mathrm{CH}_{4}$ : green up triangles, $\mathrm{CH}_{3} \mathrm{~F}$ : red circles, $\mathrm{CH}_{2} \mathrm{~F}_{2}$ : black squares, $\mathrm{CHF}_{3}$ : blue down triangles, $\mathrm{CF}_{4}$ : orange diamonds. The lines connecting the points are just guides to the eye. The arrows indicate the systems that are used for detailed analyses (see the text).

Figure 2. Molecular number density profile of $\mathrm{CH}_{4}$ (top panel) and $\mathrm{CF}_{4}$ (bottom panel) along the surface normal axis, $\mathrm{X}$, as obtained from our simulations with 5-5 selected chemical potential values. The thick dashed black lines show the water number density profile close to the ice surface, for reference. The insets show the adsorbate density profiles in the middle of the vapor/gas phase on a magnified scale. All profiles shown are averaged over the two ice surfaces present in the basic simulation box.

Figure 3. Adsorption isotherms of the five adsorbates considered, shown in the conventional surface excess vs. relative pressure form. $\mathrm{CH}_{4}$ : green up triangles, $\mathrm{CH}_{3} \mathrm{~F}$ : red circles, $\mathrm{CH}_{2} \mathrm{~F}_{2}$ : black squares, $\mathrm{CHF}_{3}$ : blue down triangles, $\mathrm{CF}_{4}$ : orange diamonds. The lines connecting the points are just guides to the eye. The dashed lines show the Langmuir isotherms fitted to the low pressure part of the $\mathrm{CH}_{3} \mathrm{~F}$ (red), $\mathrm{CH}_{2} \mathrm{~F}_{2}$ (black), and $\mathrm{CHF}_{3}$ (blue) data.

Figure 4. Instantaneous equilibrium snapshots of 3-3 systems containing (a) $\mathrm{CH}_{3} \mathrm{~F}$, (b) $\mathrm{CH}_{2} \mathrm{~F}_{2}$, and (c) $\mathrm{CHF}_{3}$ molecules as adsorbates, as obtained from our simulations. The snapshots show the upper leaflet of the systems, from side view. O, H, and F atoms are shown by red, grey, and yellow balls, respectively. Top panels show systems with relatively low surface coverage (i.e., MF2, MeF2, and FF2), middle panels show systems just below the point of condensation (i.e., MF4, MeF4, and FF4), while bottom panels show systems containing condensed phase of the adsorbate (i.e., MF5, MeF5, and FF5). 
Figure 5. Molecular number density profile of $\mathrm{CH}_{3} \mathrm{~F}$ (top panel), $\mathrm{CH}_{2} \mathrm{~F}_{2}$ (middle panel) and $\mathrm{CHF}_{3}$ (bottom panel) along the surface normal axis, $\mathrm{X}$, as obtained from our simulations of systems MF1, MeF1 and FF1 (solid red lines), MF2, MeF2 and FF2 (dashed green lines), MF3, MeF3 and FF3 (dash-dotted blue lines), MF4, MeF4 and FF4 (dash-dot-dotted orange lines), and MF5, MeF5 and FF5 (magenta circles). The thick dashed black lines show the water number density profile close to the ice surface, for reference. The dotted vertical lines mark the boundary of the first molecular layer. The inset shows the water number density profile in the entire ice phase of system MF1. All profiles shown are averaged over the two ice surfaces present in the basic simulation box.

Figure 6. Orientational maps of (a) $\mathrm{CH}_{3} \mathrm{~F}$, (b) $\mathrm{CH}_{2} \mathrm{~F}_{2}$, and (c) $\mathrm{CHF}_{3}$ molecules, located in the first molecular layer at the ice surface, as obtained at various chemical potential values (top part of the panels). Lighter shades of grey correspond to higher probabilities. The figure also shows the definition of the local Cartesian frames fixed to the individual $\mathrm{CH}_{3} \mathrm{~F}, \mathrm{CH}_{2} \mathrm{~F}_{2}$, and $\mathrm{CHF}_{3}$ molecules and of the polar angles $\vartheta$ and $\phi$ (bottom left part of the panels), and also the preferred orientations of the adsorbed molecules and their possible hydrogen bonding patterns with surface waters, aligned in one of their four preferred orientations (Ref. [!20]) (bottom right part of the panels). $\underline{X}$ is the surface normal vector, pointing from the ice to the adsorbate phase. Color coding of the atoms is the same as in Fig. 4.

Figure 7. Distribution of the total binding energy (i.e., interaction energy with the rest of the system, bottom panels) of an adsorbed molecule belonging to the first molecular layer at the ice surface, and of its contributions coming from the interaction with the other adsorbed molecules (middle panels) and with the ice phase (top panels), as obtained for the adsorption of (a) $\mathrm{CH}_{3} \mathrm{~F}$, (b) $\mathrm{CH}_{2} \mathrm{~F}_{2}$, and (c) $\mathrm{CHF}_{3}$ in systems MF1, MeF1 and FF1 (solid red lines), MF2, MeF2 and FF2 (dashed green lines), MF3, MeF3 and FF3 (dash-dotted blue lines), MF4, MeF4 and FF4 (dash-dot-dotted orange lines), and MF5, MeF5 and FF5 (magenta circles). 
Figure 1

Sumi et al.

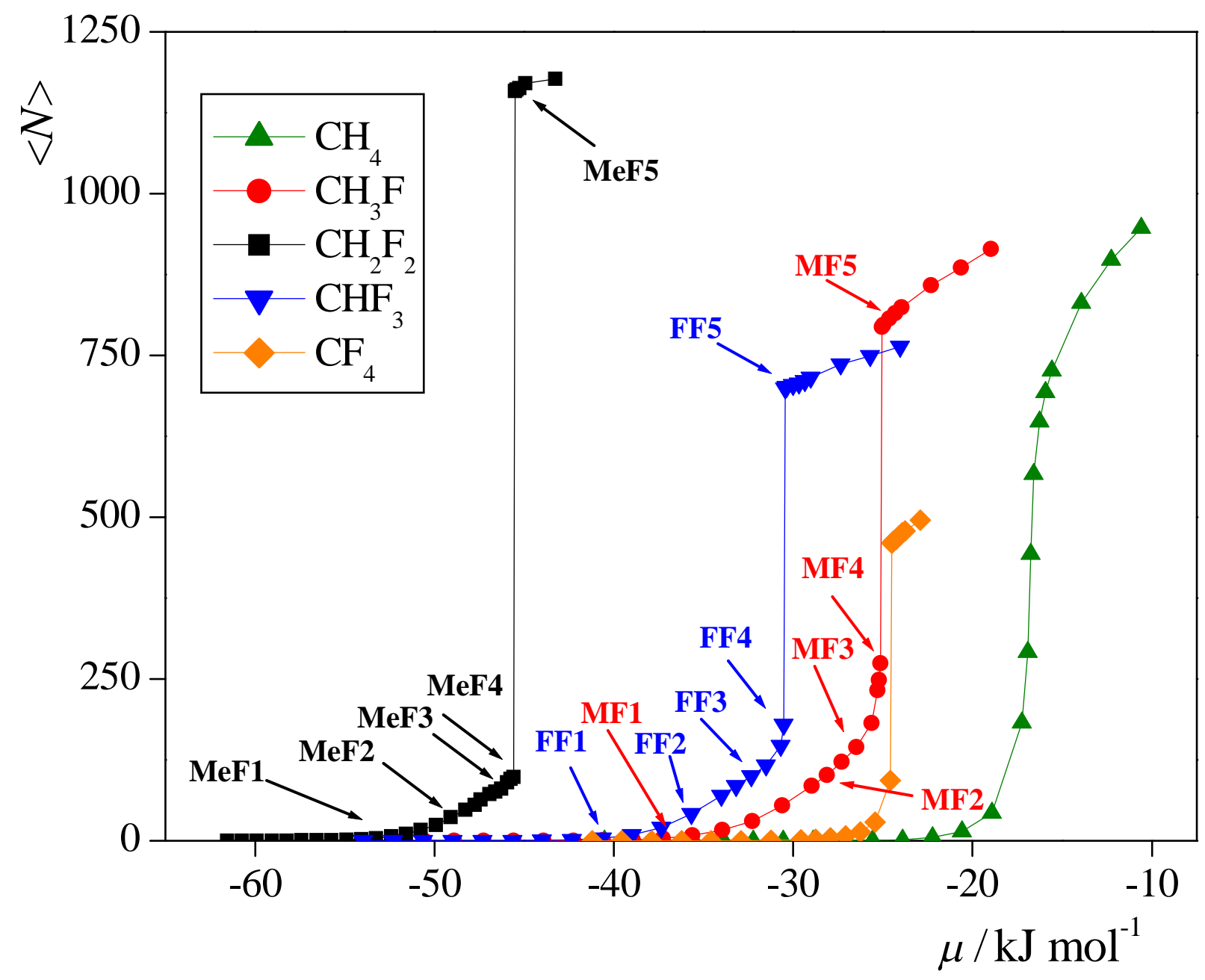


Figure 2

Sumi et al.

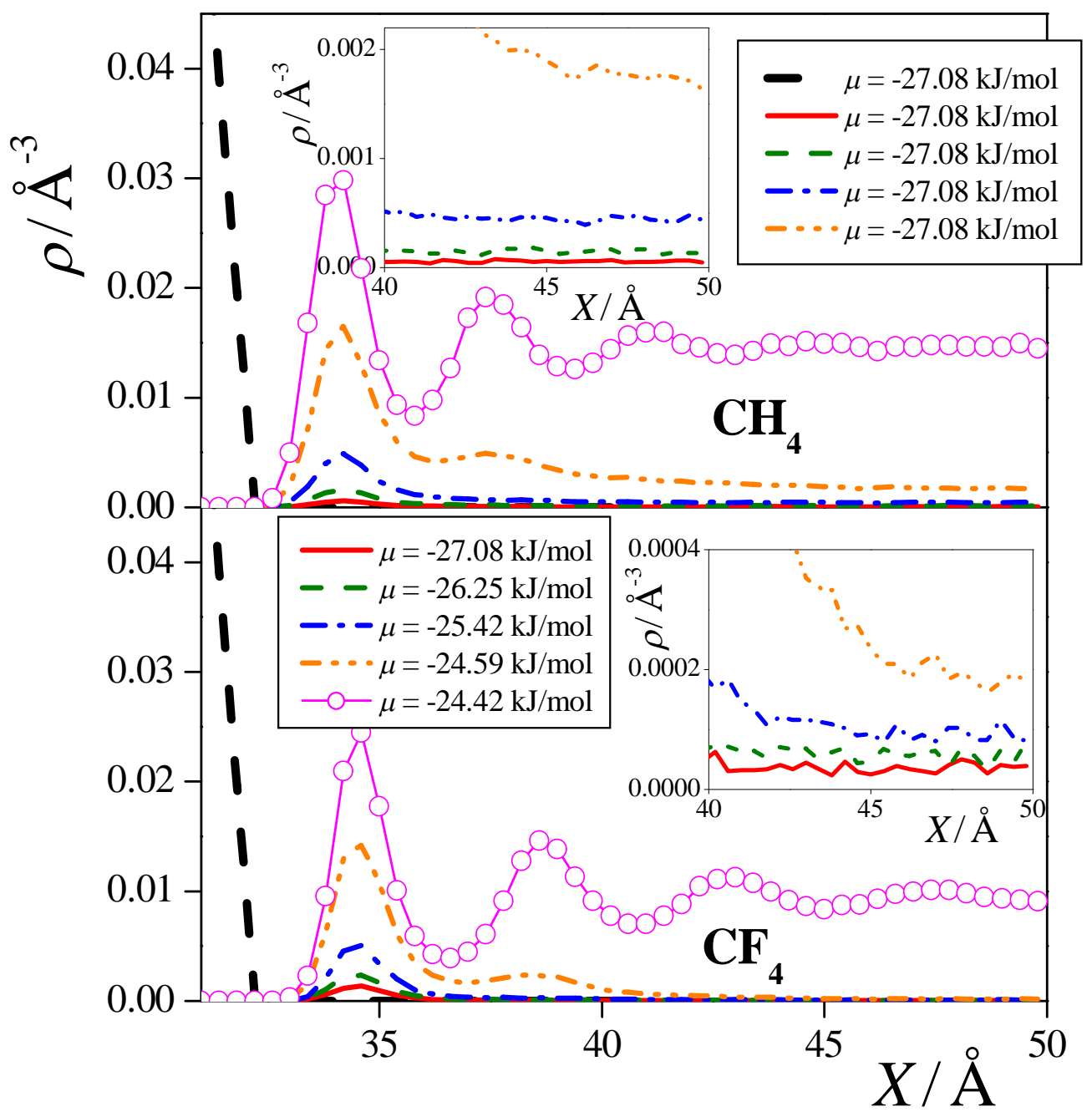


Figure 3

Sumi et al.

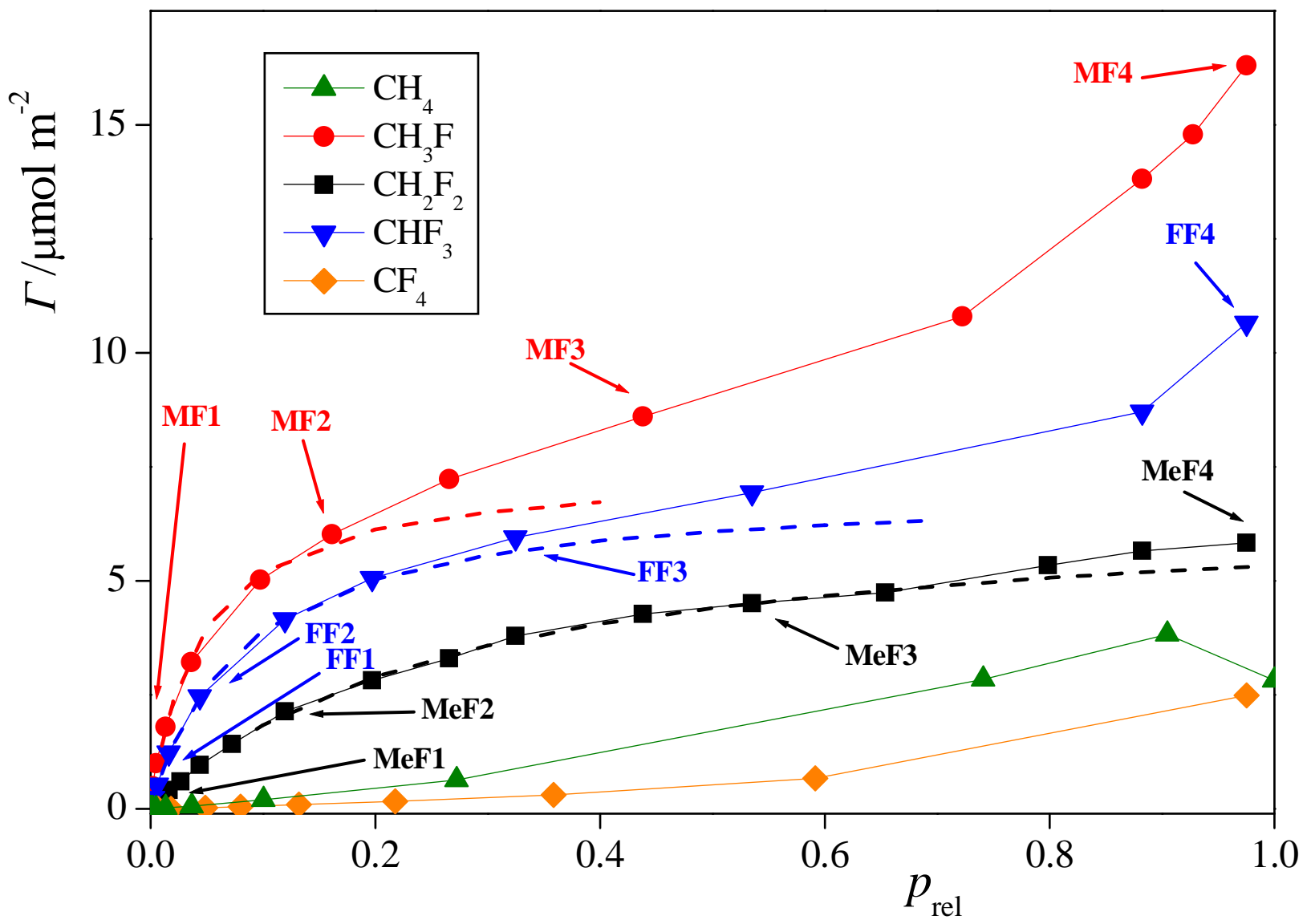




\section{$\mathrm{CH}_{3} \mathrm{~F}$}

Figure 4.a

Sumi et al.

\section{MF2 \\ $\mu=-28.12 \mathrm{~kJ} / \mathrm{mol}$}

MF4

$\mu=-25.13 \mathrm{~kJ} / \mathrm{mol}$

MF5

$\mu=-24.97 \mathrm{~kJ} / \mathrm{mol}$
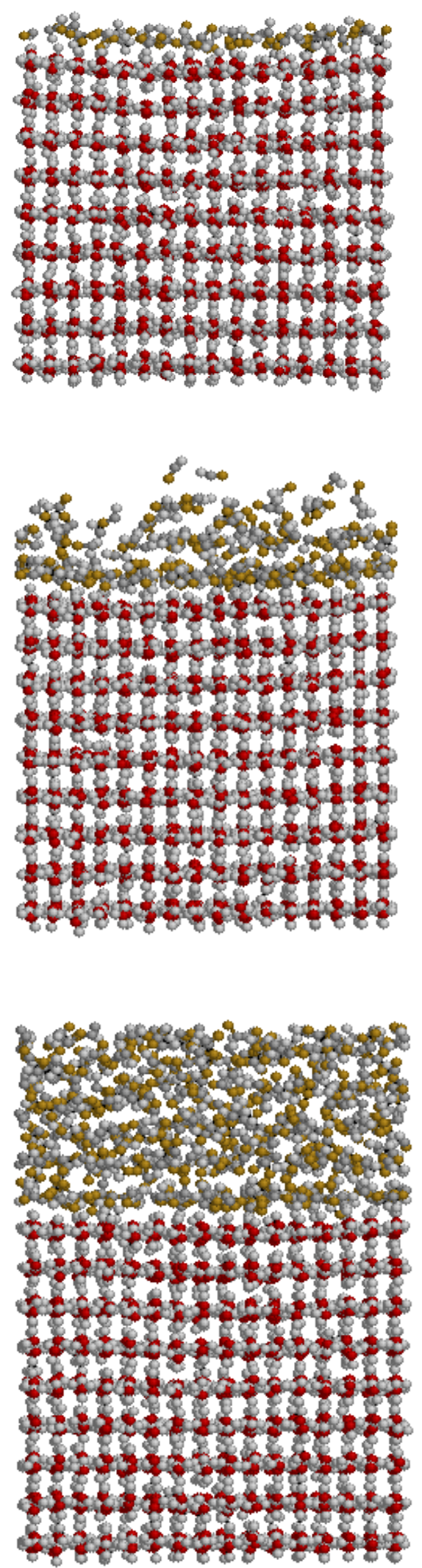


\section{$\mathrm{CH}_{2} \mathrm{~F}_{2}$}

Figure 4.b

Sumi et al.

\section{MeF2 \\ $\mu=-49.09 \mathrm{~kJ} / \mathrm{mol}$}
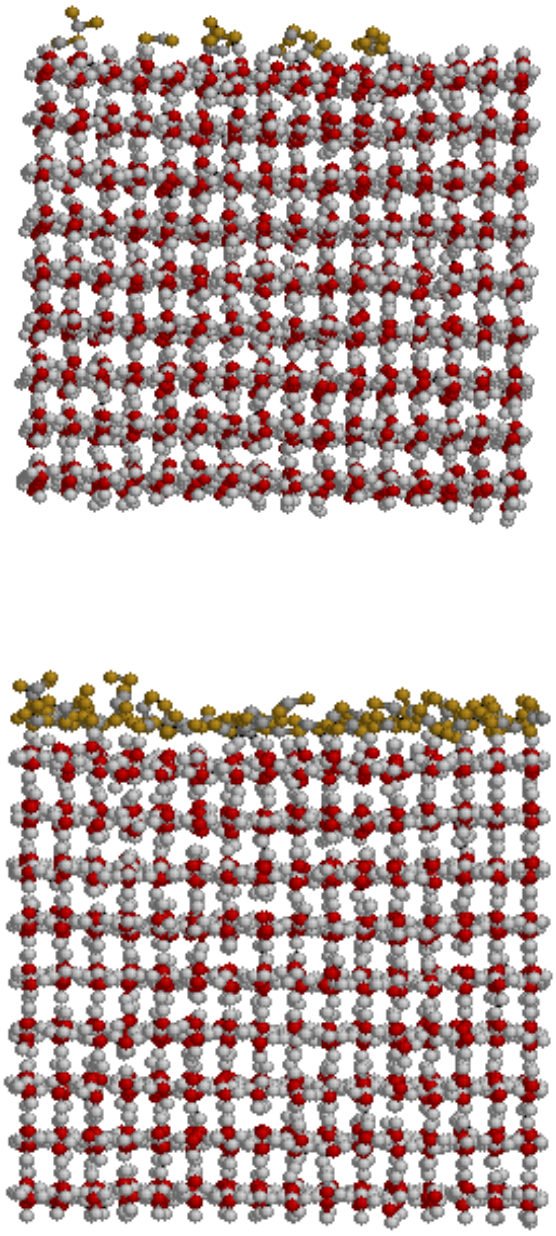


\section{$\mathrm{CHF}_{3}$}

FF2

$\mu=-35.67 \mathrm{~kJ} / \mathrm{mol}$
FF4

$\mu=-30.52 \mathrm{~kJ} / \mathrm{mol}$
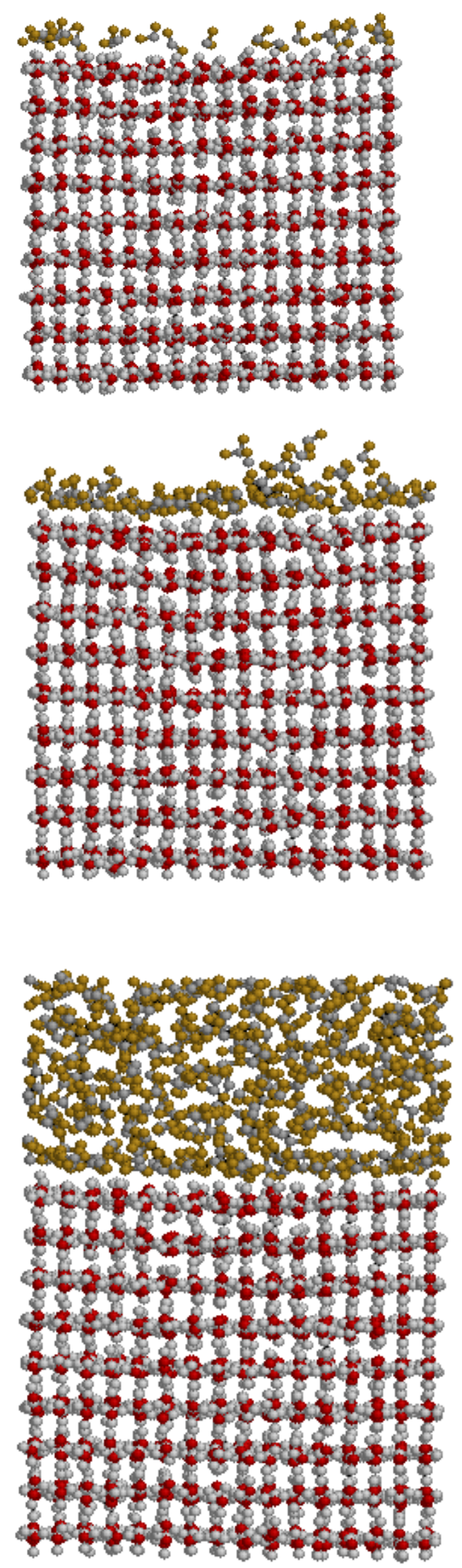

Figure 4.c

Sumi et al. 
Figure 5

Sumi et al.

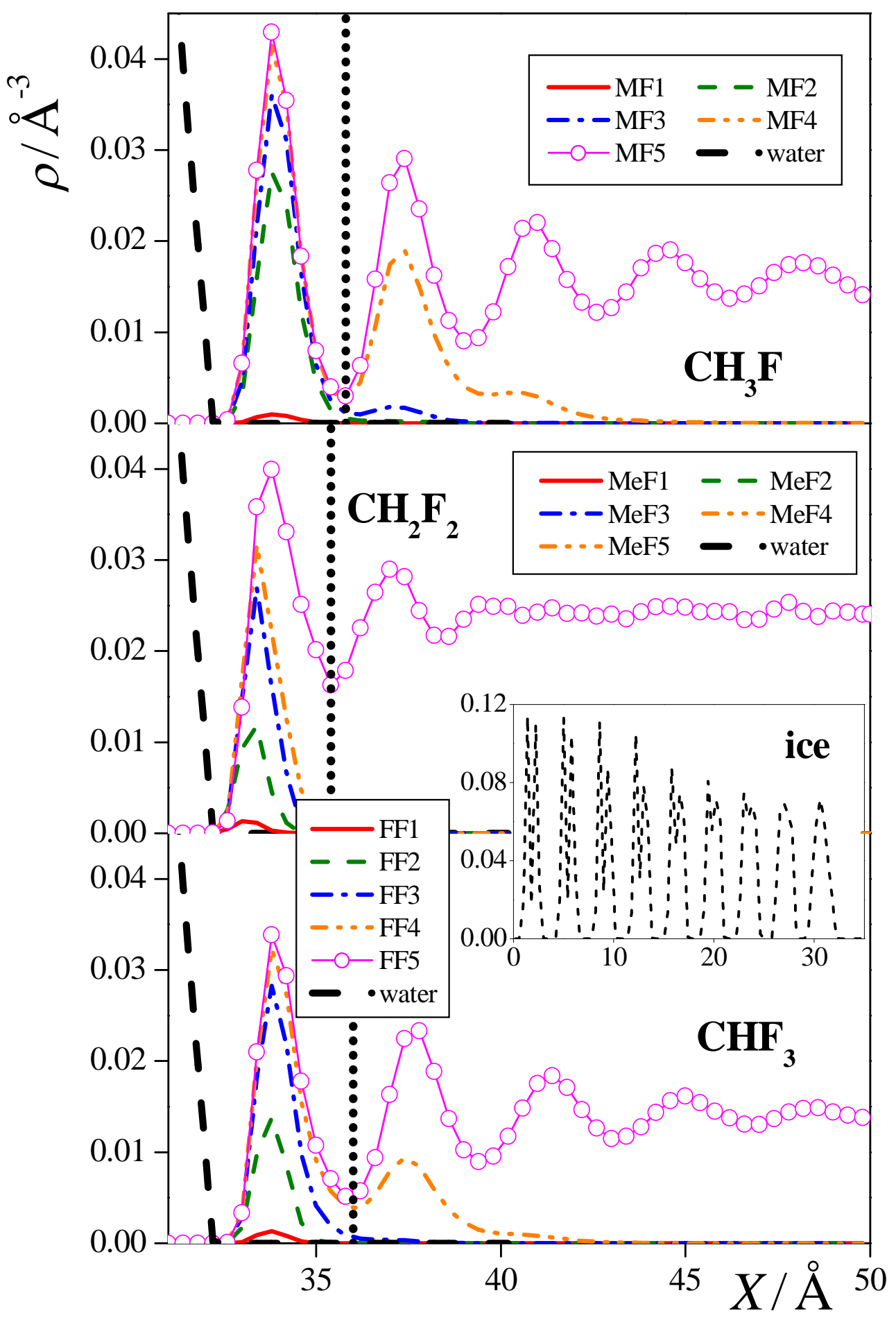


Figure 6.a

Sumi et al.

MF1
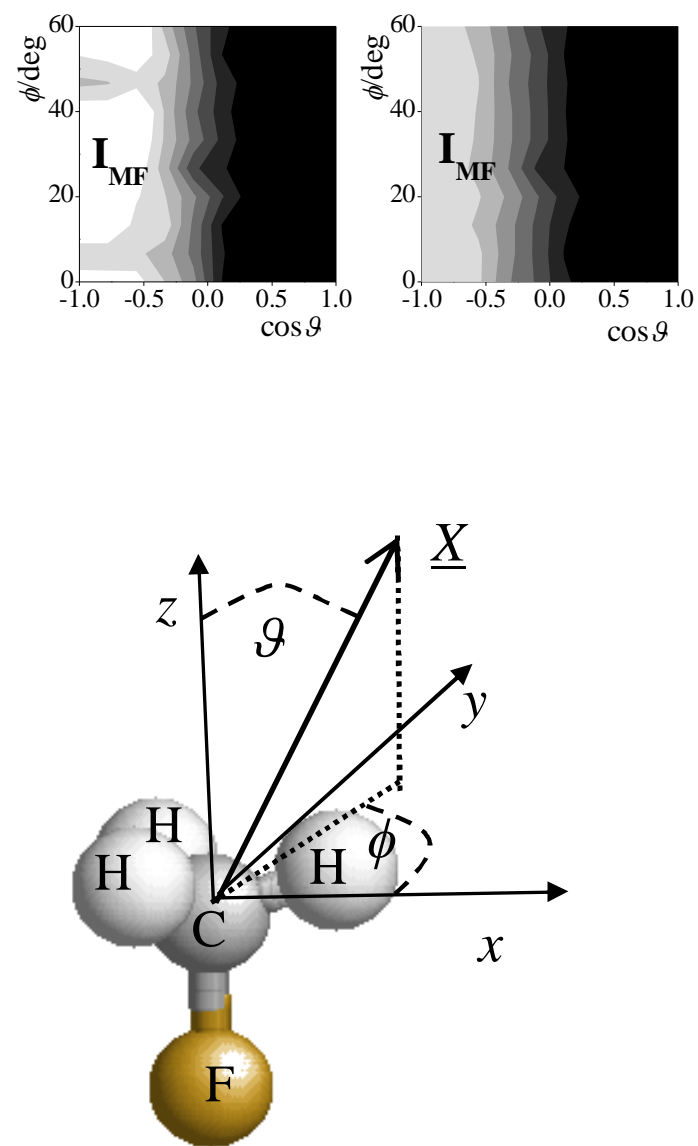

MF3
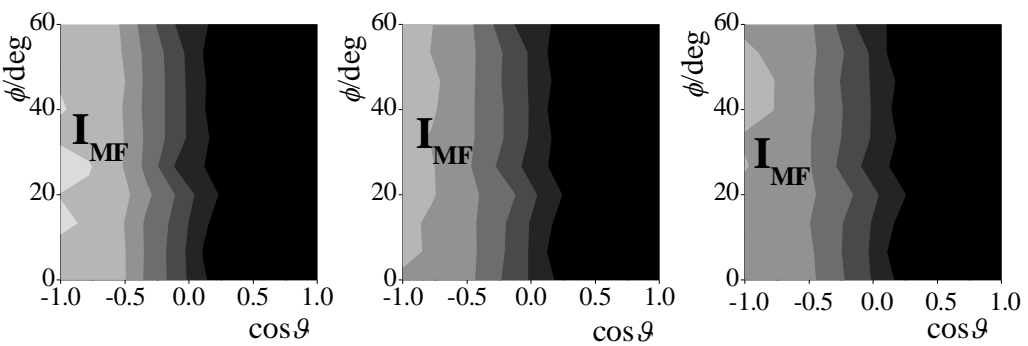
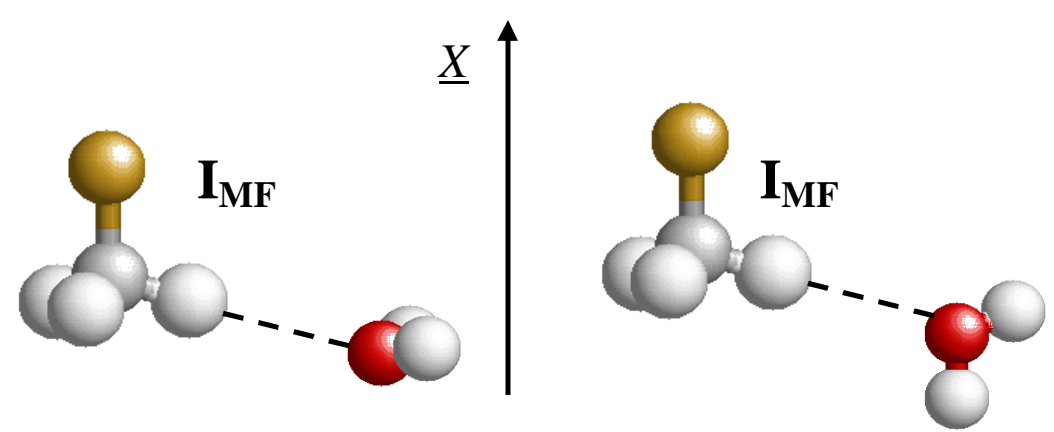
Figure 6.b

Sumi et al.

MeF1
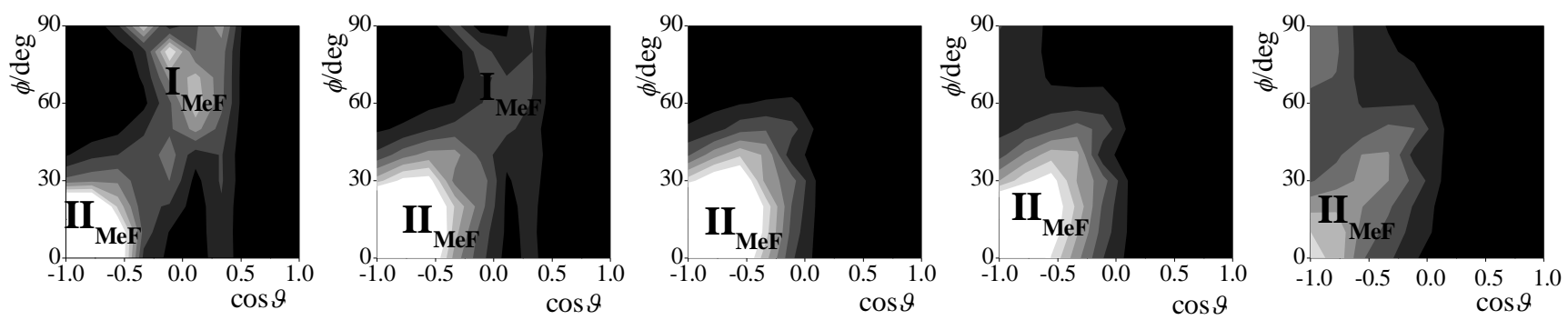
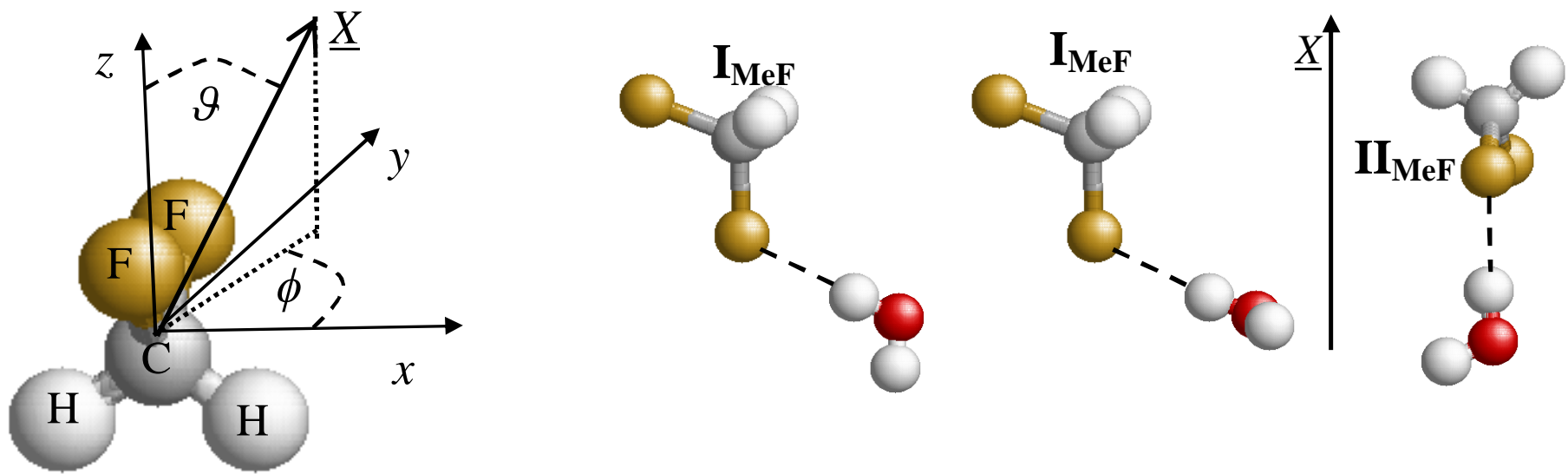
Figure 6.c

Sumi et al.

FF1
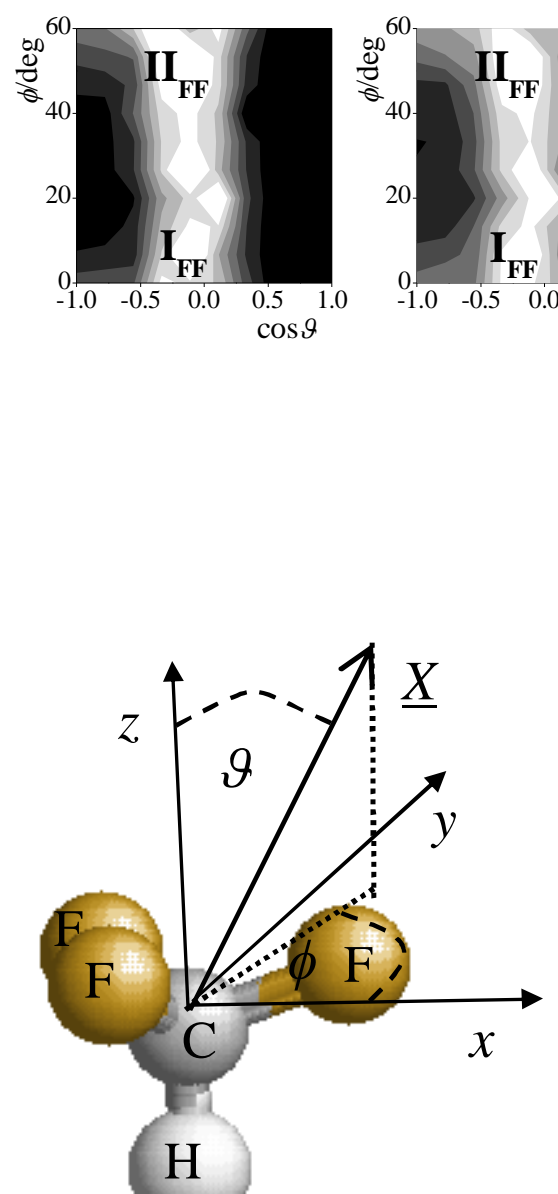

FF2
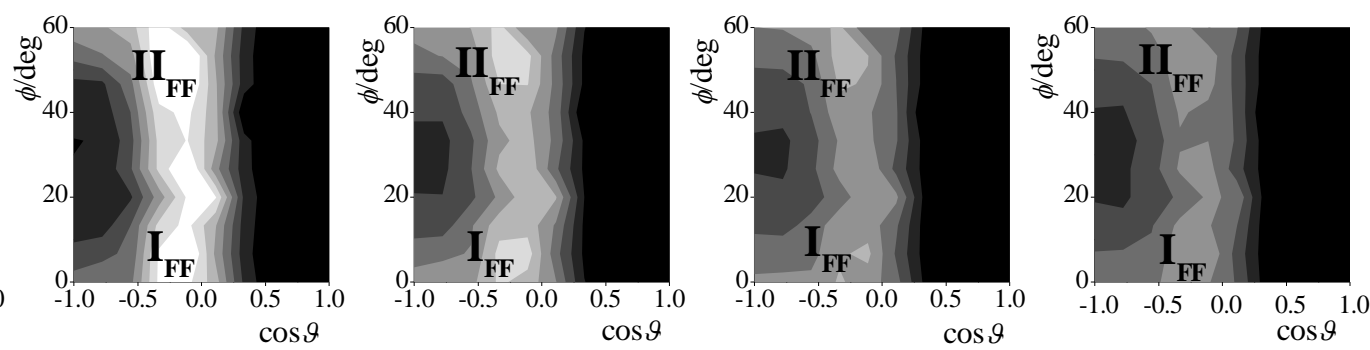

FF4

FF5

FF3

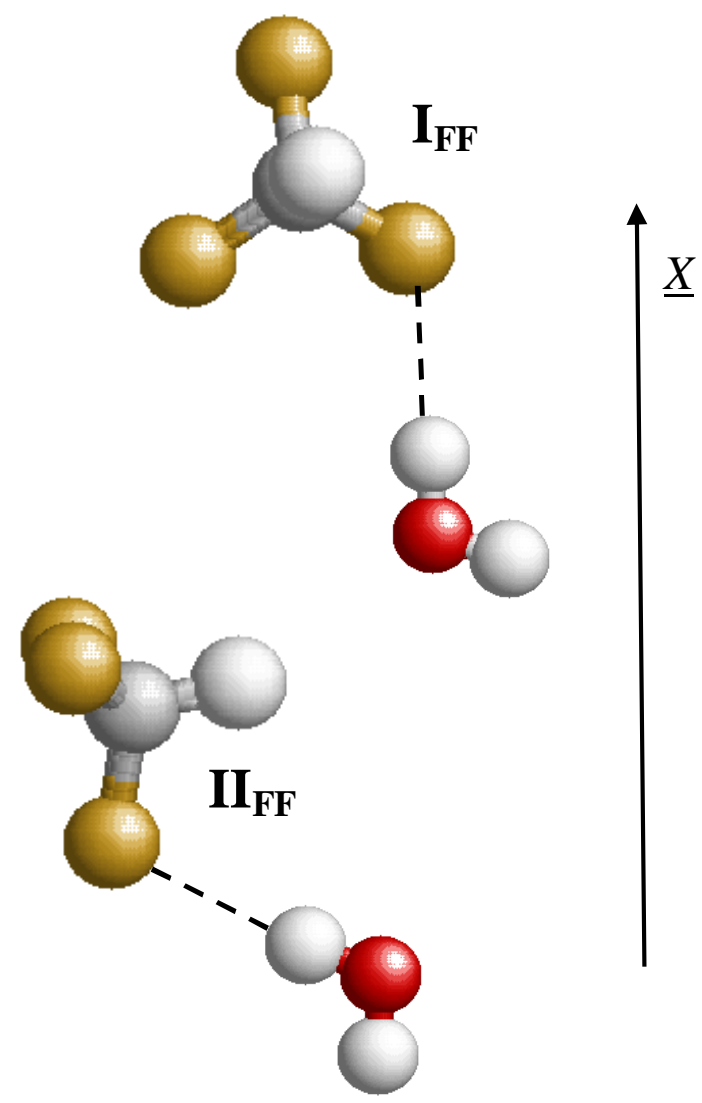

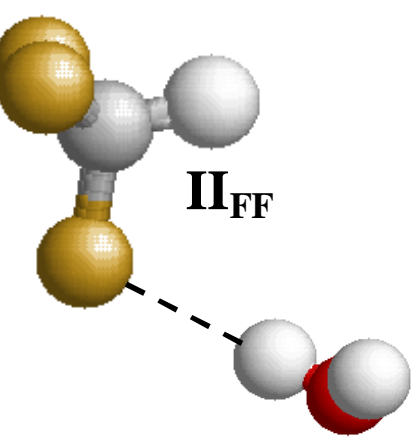


Figure 7.a

Sumi et al.

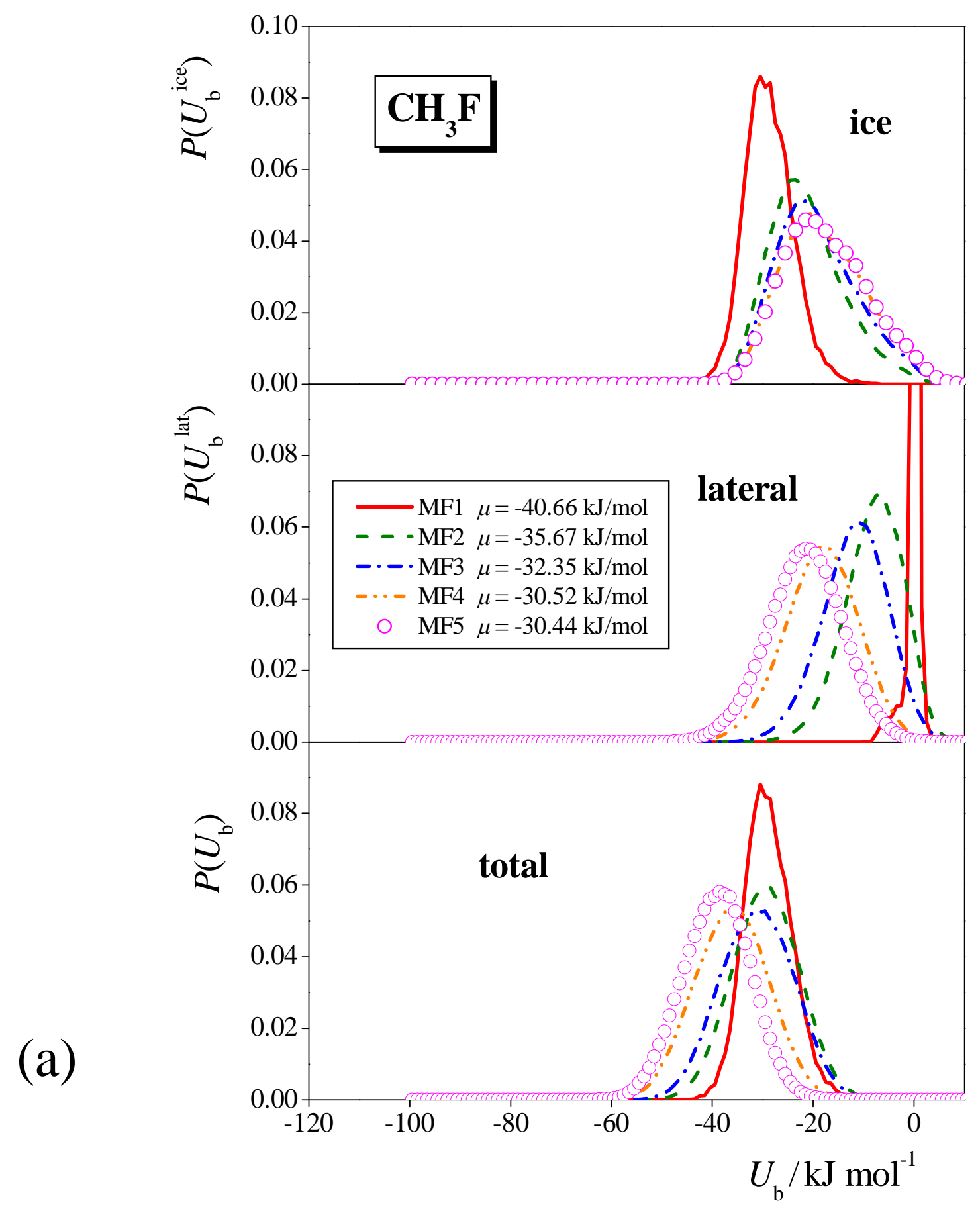


Figure 7.b

Sumi et al.

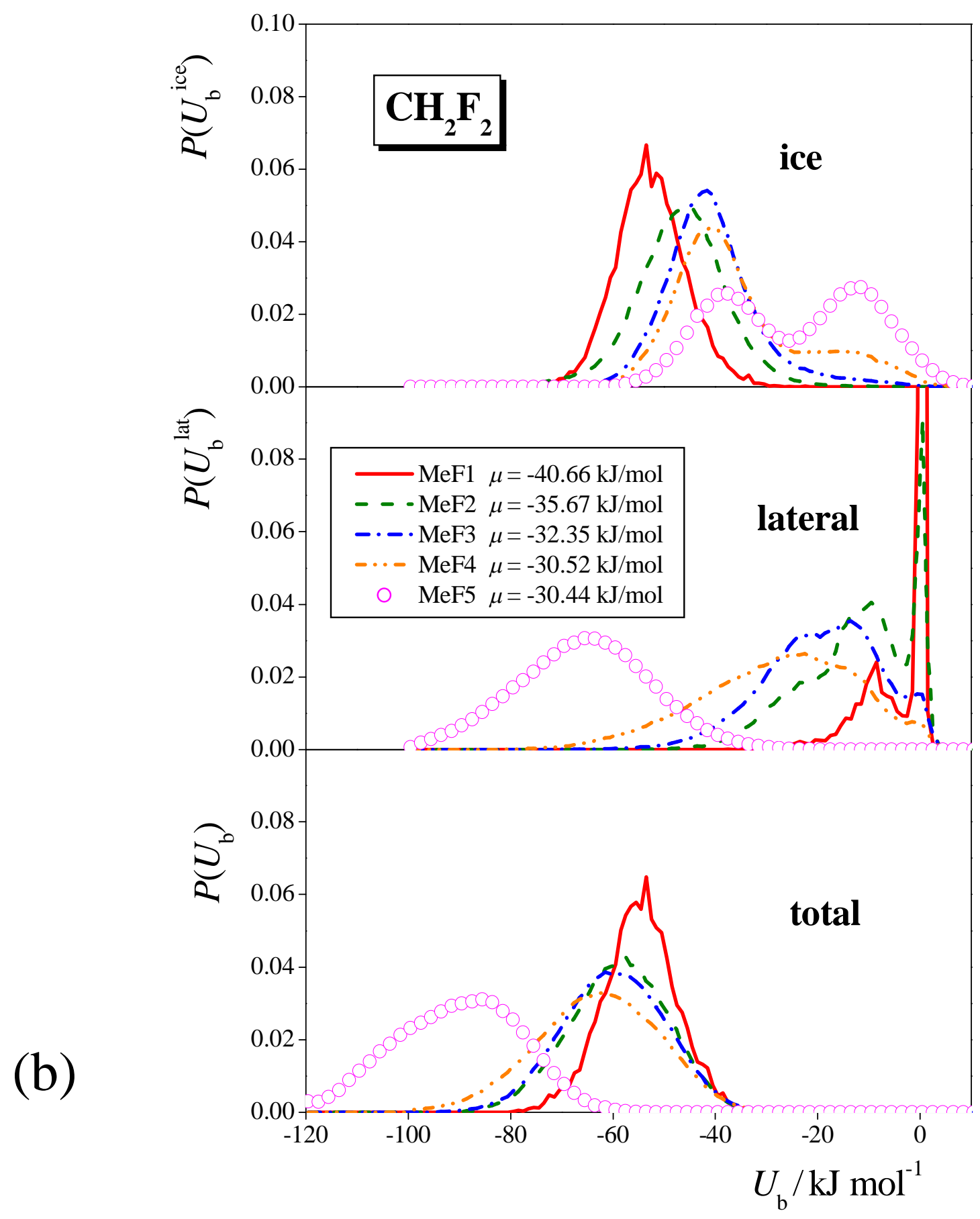


Figure 7.c

Sumi et al.

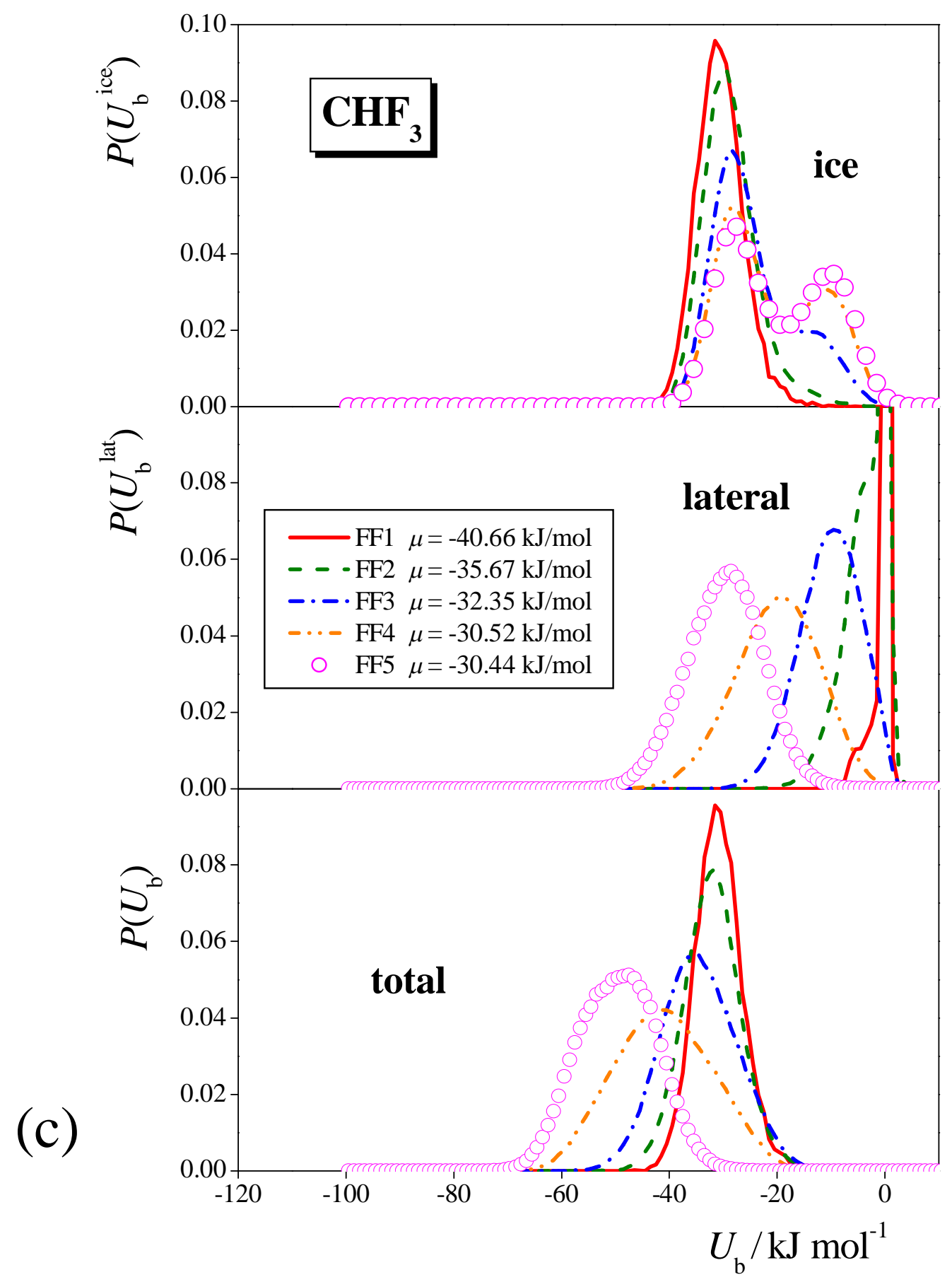


Table of Contents Graphics:

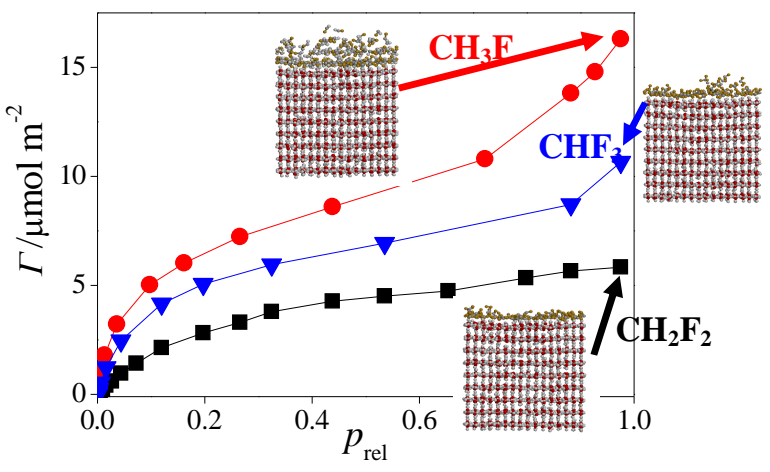

